\title{
Synthetic Polymer Aerogels in Particulate Form
}

\author{
Patrina Paraskevopoulou * , Despoina Chriti, Grigorios Raptopoulos ${ }^{\mathbb{D}}$ and George C. Anyfantis \\ Laboratory of Inorganic Chemistry, Department of Chemistry, National and Kapodistrian University of Athens, \\ Panepistimiopolis Zografou, 15771 Athens, Greece; chritides@chem.uoa.gr (D.C.); \\ grigorisrap@chem.uoa.gr (G.R.); gc.anyfantis@gmail.com (G.C.A.) \\ * Correspondence: paraskevopoulou@chem.uoa.gr; Tel.: +30-210-727-4381; Fax: +30-210-727-4782
}

Received: 28 March 2019; Accepted: 6 May 2019; Published: 10 May 2019

\begin{abstract}
Aerogels have been defined as solid colloidal or polymeric networks of nanoparticles that are expanded throughout their entire volume by a gas. They have high surface areas, low thermal conductivities, low dielectric constants, and high acoustic attenuation, all of which are very attractive properties for applications that range from thermal and acoustic insulation to dielectrics to drug delivery. However, one of the most important impediments to that potential has been that most efforts have been concentrated on monolithic aerogels, which are prone to defects and their production requires long and costly processing. An alternative approach is to consider manufacturing aerogels in particulate form. Recognizing that need, the European Commission funded "NanoHybrids", a 3.5 years project under the Horizon 2020 framework with 12 industrial and academic partners aiming at aerogel particles from bio- and synthetic polymers. Biopolymer aerogels in particulate form have been reviewed recently. This mini-review focuses on the emerging field of particulate aerogels from synthetic polymers. That category includes mostly polyurea aerogels, but also some isolated cases of polyimide and phenolic resin aerogels. Particulate aerogels covered include powders, micro granules and spherical millimeter-size beads. For the benefit of the reader, in addition to the literature, some new results from our laboratory concerning polyurea particle aerogels are also included.
\end{abstract}

Keywords: aerogels; polyurea; polyimide; phenolic resin; polybenzoxazine; resorcinol-formaldehyde; particles; beads

\section{Introduction}

Aerogels have been defined as solid colloidal or polymeric networks of nanoparticles expanded throughout their entire volume by a gas [1,2]. With silica aerogels as a well-known example, aerogels have been called "frozen smoke", and in practice they are highly open porous ultra-lightweight materials [3-5], consisting of up to more than $90 \% \mathrm{v} / \mathrm{v}$ of empty space. They are prepared by removing pore-filling solvents from wet-gels without substantial volume reduction or network compaction. Typically, that is carried out by turning the pore-filling solvent into a supercritical fluid that is released slowly like a gas. That process allows aerogels to retain the structural shape of their wet-gel precursors [5].

Silica aerogels were first prepared by S. S. Kistler in the 1930s [6,7]. Besides silica, he successfully prepared other metal oxide aerogels along with some organic aerogels $[8,9]$. Kistler's first silica aerogels were commercialized through Monsanto Chemical Company [10]. However, time-consuming gelation and solvent exchanges were the main drawbacks of Kistler's method. A new method for aerogels synthesis using alkoxides as precursors was published by J. B. Peri in 1966 [11]. Research efforts have subsequently extended this class of materials to non-silica inorganic oxides, natural and synthetic organic polymers, carbons, metals and ceramic materials [12].

As with any porous material, the bulk physical properties are influenced by the size and shape of the pores. Most aerogels are mesoporous materials with pore sizes in the 2-50 $\mathrm{nm}$ range. 
The solid network has a complex hierarchical structure coming from aggregation of smaller primary particles to fractal porous secondary particles, eventually agglomerating to a structure resembling a "pearl-necklace". The finely structured porous skeletal framework together with the small size pores provides aerogels with high surface areas, low thermal conductivities, low dielectric constants, and high acoustic attenuation [4,13-15]. Those properties make aerogels promising materials for a wide variety of areas, including, but not limited to, energy storage [16-19], thermal [18,20-25] and acoustic insulation [20,21], dielectrics [20], gas and humidity adsorption [20,24,26], for space applications [20], gas sensors [26], environmental remediation [27,28], catalysis [4,17,24,26,29-31], biomedicine [19,25,32], and the food industry [24,32]. However, monolithic aerogels are prone to cracks and defects [33] and their production requires long processing times, which may hinder their potential. One way toward efficient preparation and processing is to consider manufacturing aerogels in particulate rather than in monolithic form [34]. In response to that need, the European Commission is funding "NanoHybrids" [35], a 3.5 year program under the Horizon 2020 framework with 12 industrial and academic partners aiming at the development of technology for aerogel particles production from bioand synthetic polymers. The production of biopolymer aerogels in particulate form [36-38] has been reported in recent publications. Synthetic polymer aerogels in powder, micro granule and spherical millimeter-size bead form are reviewed here.

Silica aerogels, arguably the archetypical example of aerogels, have been synthesized as monoliths (relatively difficult to manufacture in cm-size and above), composite blankets (the main product of the aerogel thermal insulation industry), and as powders and granules (also commercially available) [39]. For certain applications, particulate aerogels are preferable over monoliths. For example, silica aerogel microspheres $(120 \pm 30 \mu \mathrm{m}$ in diameter; mean pore size: $14 \mathrm{~nm})$ perform better than silica aerogel monoliths toward filtration of air to remove latex spheres $(20-2000 \mathrm{~nm})$ [40], and silica aerogel granules (150-250 $\mu \mathrm{m}$ and 50-500 $\mu \mathrm{m}$ ) outperform high efficiency particulate air (HEPA) filters in solid and oily aerosol collection [41]. Silica aerogel granules $(0.01-4 \mathrm{~mm})$ have also shown high thermal insulation (thermal conductivity as low as $0.019 \mathrm{~W} \mathrm{~m}^{-1} \mathrm{~K}^{-1}$ ) as well as acoustic insulation (transmission loss as high as $15 \mathrm{~dB}$ at $1700 \mathrm{~Hz}$ ) properties, both improving with decreasing size and increasing packing density of the granules [42]. Hollow and granular silica aerogel microspheres have been prepared from rice husk ash and have found applications in drug delivery [43].

Silica aerogel microparticles ( $155 \mu \mathrm{m}$ to $1.7 \mathrm{~mm}$ ) have been synthesized from tetramethylorthosilicate via emulsion gelation and $\mathrm{CO}_{2}$ supercritical extraction [44]. Silica aerogel granules have been prepared from polyethoxysiloxanes in a one-pot process requiring minimal amounts of solvent and processing time [45]. Uniform mm-sized silica aerogel beads have been synthesized from sodium silicate and tetraethoxysilane (hydrophobic beads), or from trimethylchlorosilane (hydrophilic beads) [46], or from tetraethoxysilane by extrusion of the silica sol into an oil phase through nozzles [47].

Carbon aerogel beads have been prepared by pyrolysis of resorcinol-formaldehyde [48-53] or polybenzoxazine [54] beads. This kind of aerogels are chemically inert, have high electric conductivity and adjustable internal characteristics; thus, they can find applications in electrodes or in supercapacitors $[49,51,52]$, with specific capacitance as high as $215 \mathrm{~F} \mathrm{~g}^{-1}$ [49]. They have also been applied as adsorbents for phenol, with adsorption capacity of $29.3 \mathrm{mg} \mathrm{g}^{-1}$ [53].

In that regard, although there is a vast literature for monolithic aerogels derived from synthetic polymers, including aerogels based on phenolic resins (e.g., resorcinol-formaldehyde [19,55-61], polybenzoxazines [62-66], polyureas [67-69], polyimides [70-74], polyamides (Kevlar ${ }^{\mathrm{TM}}$-like) [74-76], polyurethanes [77-83], as well as aerogels derived via Ring Opening Metathesis Polymerization (ROMP), including polynorbornene and polydicyclopentadiene [81,84-87], only a few examples of synthetic polymer aerogel particles are known, and they have become the subject of this mini-review. Those polymeric materials include mostly polyurea aerogels, and a few examples of polyimide and phenolic resin aerogels. Phenolic resin aerogel beads were synthesized as precursors of carbon aerogels in bead form, and characterization was mainly focused on the carbons. 


\section{Polyurea (PUA) Aerogels}

Polyureas (PUA) are a class of polymers that can be defined as the product of the reaction between an isocyanate and an amine, as shown in Scheme 1a. PUA can be a good elastomer, with good mechanical properties, chemical stability, thermal shock abrasion resistance, flexibility and water repellence. Those properties depend on the chemical identity and structure of isocyanates and amines, hydrogen bonding and the polymerization conditions. The nucleophilic addition of the amine to the isocyanate is fast and catalyst-free (aromatic isocyanates are more reactive than aliphatic ones because of the electron-withdrawing properties of the aromatic groups), which are advantages for the production of aerogels using sol-gel processing.

(a)

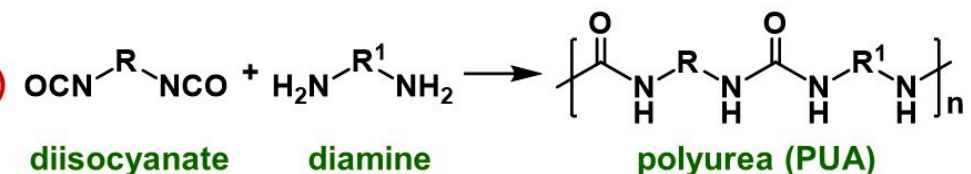

(b)

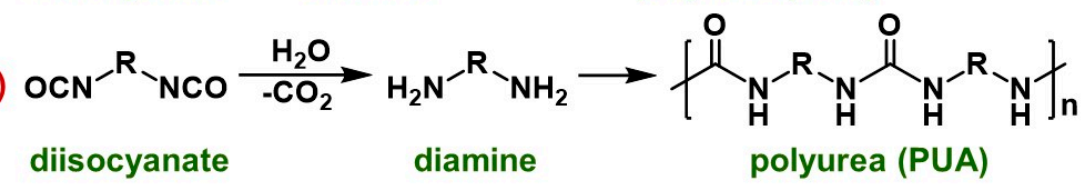

(c)

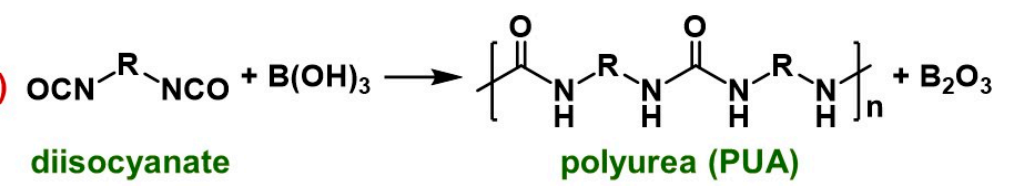

Scheme 1. Synthesis of PUA aerogels from isocyanates and amines (a), isocyanates and water (b), or isocyanates and boric acid (c).

In a more economical approach, PUA can also be formed from the reaction of isocyanates with water, as shown in Scheme 1b [67]. Isocyanates and water form unstable carbamic acids, which decompose by eliminating carbon dioxide and yield amines. Those amines react with the remaining isocyanates yielding ureas. Although this route to ureas needs a catalyst (triethylamine), it is advantageous because it bypasses the use of multifunctional amines, which can be expensive. Aerogels prepared from the reaction of triisocyanate Desmodur N3300 (Scheme 2) with water showed that their nanomorphology depended on the concentration of the isocyanate in the sol and was nearly independent of the concentrations of water and catalyst, which mainly affected the gelation time and the density of the materials. By replacing the triisocyanate Desmodur N3300 with the more rigid aromatic Desmodur RE (Scheme 2), the skeletal framework seemed more particulate than fibrous, even at lower densities. Additionally, variations on the nanomorphology of the porous samples can be achieved with different gelation solvents [68]. 


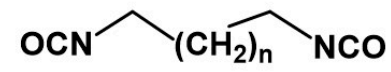

1,4-diisocyanatobutane $\mathrm{n}=2$, BDI

hexamethylene diisocyanate $\mathrm{n}=4$, HDI

1,8-diisocyanatooctane $n=6$, ODI

1,12-diisocyanatododecane $\mathrm{n}=10$, DDI

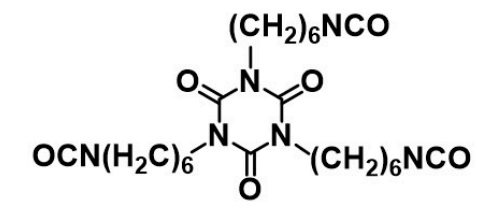

hexamethylene diisocyanate trimer Desmodur N3300

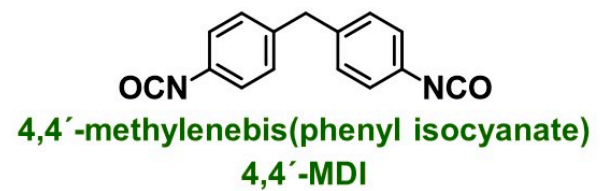<smiles>Cc1ccc([N+](=O)[O-])cc1[N+](=O)[O-]</smiles>

toluene 2,4-diisocyanate 2,4-TDI

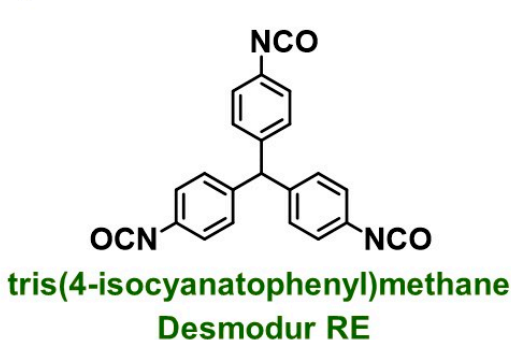

Scheme 2. Structures of the di- and triisocyanates used for the synthesis of the materials discussed in this review.

Another approach is the synthesis of PUA aerogels from the reaction of Desmodur RE with anhydrous $\mathrm{H}_{3} \mathrm{BO}_{3}$ (Scheme 1c) [69]. The by-product, $\mathrm{B}_{2} \mathrm{O}_{3}$, is soluble and could be easily washed off the porous network, leaving behind pure PUA. The same reaction proceeded with a number of mineral acids, such as $\mathrm{H}_{3} \mathrm{PO}_{4}, \mathrm{H}_{3} \mathrm{PO}_{3}, \mathrm{H}_{2} \mathrm{SeO}_{3}, \mathrm{H}_{6} \mathrm{TeO}_{6}, \mathrm{H}_{5} \mathrm{IO}_{6}$ and $\mathrm{H}_{3} \mathrm{AuO}_{3}$, but the corresponding oxides are insoluble and remained within the polymer. PUA aerogels obtained with this method were chemically identical, except in minute details at the nanoscopic level, to PUA aerogels obtained via reaction of Desmodur RE with water. That reaction pathway is distinctly different from the conventional path followed by isocyanates with carboxylic acids to amides, and has not been explored for particulate PUA aerogels yet. However, that approach is highly promising for metal- and metal-salt doped PUA aerogel beads and carbons and is currently under investigation.

\subsection{PUA Aerogel Powders and Granules}

Several PUA powders with aerogel-like internal structure have been synthesized via reaction of tetrakis(4-aminophenyl)methane (TAPM; Scheme 3) with a variety of alkyl diisocyanates (1,4-diisocyanatobutane (BDI), 1,6-diisocyanatohexane (HDI), toluene 2,4-diisocyanate (2,4-TDI), 1,8-diisocyanatooctane (ODI), 1,12-diisocyanatododecane (DDI), 4,4'-methylenebis(phenyl isocyanate) (MDI), p-phenylene diisocyanate (PDI); Scheme 2) in DMF at room temperature (r.t.), followed by precipitation induced by addition of a large volume of a non-solvent (acetone) just before gelation $[88,89]$. The precipitate was washed 3 times with acetone and was dried at $150{ }^{\circ} \mathrm{C}$ under vacuum. The product consisted of spherical particles, the size of which was larger (on the order of hundreds of nm-see Figure 1) than the gel network nanoparticles (about 9-30 nm, measured with dynamic light scattering) and depended on the chemical identity of the diisocyanate. The largest particles were obtained with the isocyanate with the largest aliphatic chain (DDI). Pore sizes were in the range of 5-9 $\AA$, with higher percentage in the range of 5-6 $\AA$ for BDI and HDI derived samples. BET surface areas measured with $\mathrm{N}_{2}$ sorption (19-68 $\mathrm{m}^{2} \mathrm{~g}^{-1}$ ) were much lower than surface areas measured with $\mathrm{CO}_{2}$ sorption $\left(170-240 \mathrm{~m}^{2} \mathrm{~g}^{-1}\right)$. On geometric grounds, and assuming a density of $1 \mathrm{~g} \mathrm{~cm}^{-3}$, it was calculated that BET surface areas corresponded to the external surface area of the particles shown in SEM. Therefore, it was concluded that micropores could be sampled only by $\mathrm{CO}_{2}$, and not by $\mathrm{N}_{2}$. Based on those differential gas sorption characteristics, it was proposed that such PUA powders are suitable for application in gas 
separations (e.g., $\mathrm{CO}_{2}, \mathrm{~N}_{2}$ and $\mathrm{CH}_{4}$ ). The best separations were achieved with TAPM-BDI derived PUA powder, which had a $\mathrm{CO}_{2} / \mathrm{N}_{2}$ selectivity of $65.5 \mathrm{~mol} \mathrm{~mol}^{-1}$ and a $\mathrm{CO}_{2} / \mathrm{CH}_{4}$ selectivity of $8.3 \mathrm{~mol} \mathrm{~mol}^{-1}$.

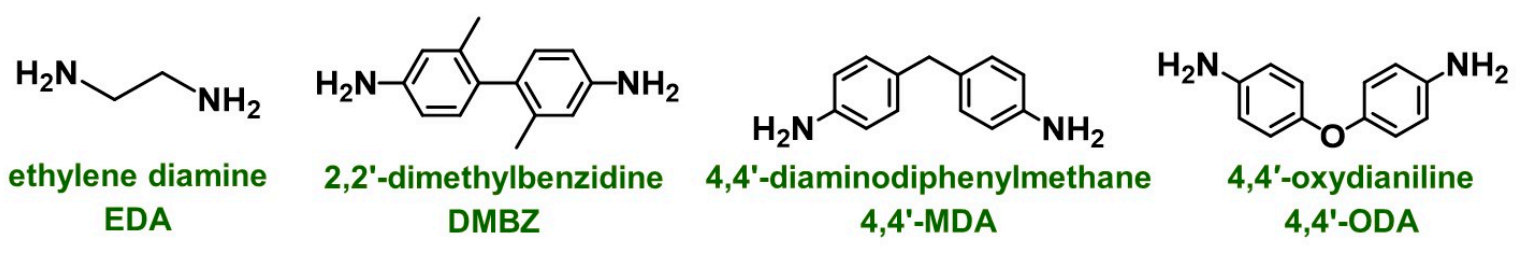<smiles>Nc1ccc(Oc2cc(Oc3ccc(N)cc3)cc(Oc3cccc(N)c3)c2)cc1</smiles><smiles>Nc1ccc(-c2cc(-c3ccc(N)cc3)cc(-c3ccc(N)cc3)c2)cc1</smiles><smiles>Nc1ccc(C(c2ccc(N)cc2)(c2ccc(N)cc2)c2ccc(N)cc2)cc1</smiles>

1,3,5-triaminophenoxybenzene $\mathrm{TAB}$

1,3,5-tris(4-aminophenyl)benzene TAPB tetrakis(4-aminophenyl)methane TAPM

Scheme 3. Structures of the di- and tetraamines used for the synthesis of the materials discussed in this review.
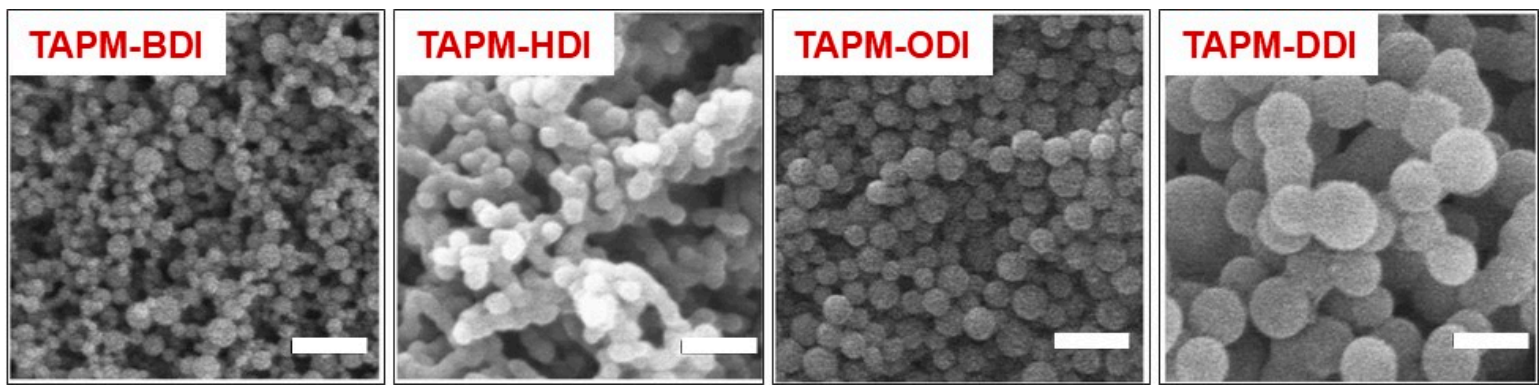

Figure 1. SEM images of PUA powders precipitated into acetone from the sols of the monomer pairs, as indicated, at $50 \%$ reaction conversion. Initial solution concentration: $0.04 \mathrm{~g} \mathrm{~mL}^{-1}$. Scale bar: $400 \mathrm{~nm}$. Adapted from Ref. [89] with permission from The Royal Society of Chemistry.

PUA powders with aerogel-like internal structure have been also produced by varying the conditions of mechanical agitation at $30^{\circ} \mathrm{C}$ of sols from 2,4-TDI (Scheme 2) and 4,4'-oxydianiline $\left(4,4^{\prime}\right.$-ODA; Scheme 3$)$ in acetone, and in selected cases also in acetonitrile [90]. The reaction was run always under conditions of precipitation polymerization. The typical total monomer concentration $\left(2,4-\mathrm{TDI}+4,4^{\prime}-\mathrm{ODA}\right)$ in the sol was $1 \% \mathrm{w} / \mathrm{w}$. Resulting powders were compared among themselves, viz. with no reference to monolithic aerogels. Precipitates were collected by centrifugation, washed with acetone and dried at $60{ }^{\circ} \mathrm{C}$ to powdery products. No application of vacuum during drying was reported. As-prepared PUA powders were thermally stable (degradation started at $260{ }^{\circ} \mathrm{C}$ ), and insoluble in several solvent systems at $70{ }^{\circ} \mathrm{C}$ under reciprocating shaking for $6 \mathrm{~h}$. Those solvent systems included acetic acid, toluene, acrylonitrile, $m$-cresol, THF, a mixture of $\mathrm{HCl}_{(\mathrm{aq})} /$ acetone $(1: 1$ $\mathrm{v} / \mathrm{v})$ and aqueous alkali $\left(1.0 \mathrm{~mol} \mathrm{~L}^{-1}\right)$. Fibrous morphologies with fiber diameters $\leq 100 \mathrm{~nm}$ were reported under conditions without stirring, stirring at low stirring rates $(100 \mathrm{rpm})$, or with reciprocating stirring. Higher stirring rates $(600 \mathrm{rpm})$ produced granular polymers. Nanomorphology, however, was a complicated function of several parameters: For example, with no stirring at all, the network nanomorphology changed from fibrous to particulate (granular aggregates) by lowering the reaction temperature from 30 to $0{ }^{\circ} \mathrm{C}$. Similarly, using reciprocated stirring, nanomorphology changed from fibrous to particulate by increasing the total monomer concentration $\left(2,4-\mathrm{TDI}+4,4^{\prime}-\mathrm{ODA}\right)$ from 1 to $5 \% \mathrm{w} / \mathrm{w}$ (Figure 2). Nanofibers were obtained with monomer concentrations lower than $2 \% \mathrm{w} / \mathrm{w}$ 
(Figure 2). Running the reaction in acetonitrile (all other parameters being the same, i.e., reciprocating stirring, [2,4-TDI $\left.\left.+4,4^{\prime}-\mathrm{ODA}\right]=1 \% \mathrm{w} / \mathrm{w}, 30^{\circ} \mathrm{C}\right)$ yielded large $(5-20 \mu \mathrm{m}$ in diameter $)$ spherical particles rather than fibers (Figure 3). Switching from fibers in acetone [67] to large micron-size particles in acetonitrile [68] has also been reported with monolithic PUA aerogels synthesized from Desmodur N3300, an aliphatic triisocyanate, and water. Overall, all morphological changes observed in PUA aerogels as a function of solvent and monomer concentration have been attributed recently to the kinetics and the mechanism of the gelation process, that is phase separation of solid colloidal particles versus liquid oligomers [91].

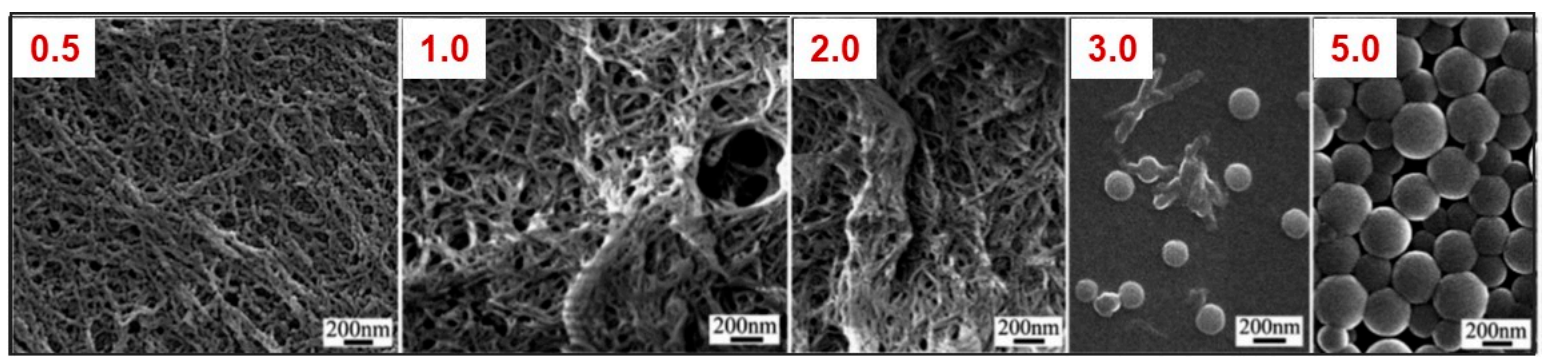

Figure 2. SEM images of the polymers prepared from the reaction of 2,4-TDI and 4,4'-ODA in acetone at $30{ }^{\circ} \mathrm{C}$ for $4 \mathrm{~h}$ under reciprocating shaking (150 oscillations per min), at five different monomer concentrations (\% w/w), as indicated. Adapted from Ref. [90] with permission from The Royal Society of Chemistry.
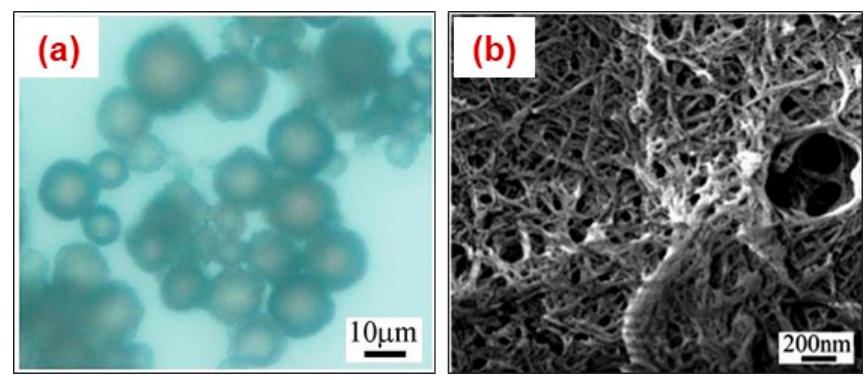

Figure 3. SEM images of PUA particles prepared at $30{ }^{\circ} \mathrm{C}$ in acetonitrile (a), and in acetone (b) under reciprocating shaking (150 oscillations per minute). Monomer concentration: $1.0 \% \mathrm{w} / \mathrm{w}$ [90]. Adapted from Ref. [90] with permission from The Royal Society of Chemistry.

PUA aerogel powders have been fabricated from the reaction of Desmodur N3300 (Scheme 2) with water in organic solvents (acetone or propylene carbonate). Three methods have been employed: vigorous agitation of the sol, suspension, and emulsion gelation, using the experimental setup shown in Figure 4. The synthetic procedures are described in the Supplementary Material section. Formulations and gelation times are reported in Tables S1-S4. Acetone was used in order to relate the properties of aerogel powders with those of monoliths from the literature [67]. Propylene carbonate was used because it is not miscible with hexane, thereby it can be used for suspension and emulsion gelation. In propylene carbonate the release of $\mathrm{CO}_{2}$ was vigorous; therefore, well-shaped monoliths could not be obtained. The concentration of the monomer (Desmodur N3300) was varied between 2.75 and $11 \%$ $\mathrm{w} / \mathrm{w}$. Wet-powders were dried with supercritical fluid (SCF) $\mathrm{CO}_{2}$ in an autoclave to provide aerogel powders or granules. 


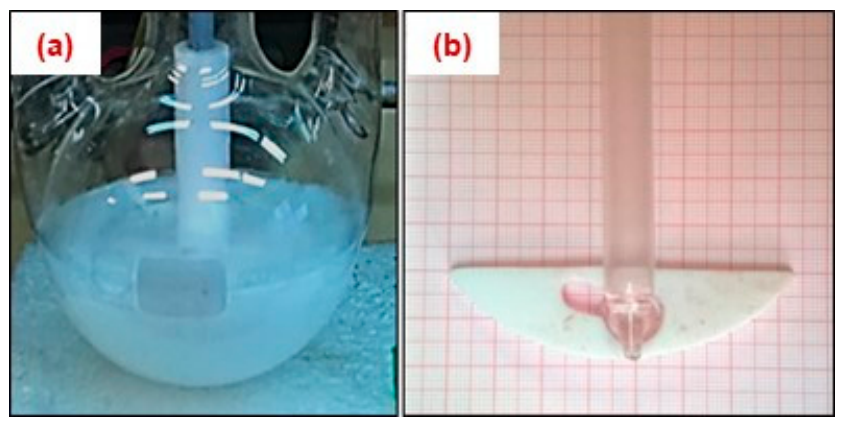

Figure 4. (a) Experimental setup for the synthesis of PUA aerogel powders with disruption of gelation (vigorous agitation, 250-300 rpm; suspension and emulsion polymerization, $400 \mathrm{rpm}$ ). (b) The half-moon shaped blade used for agitation.

For the same monomer concentration, powders obtained from propylene carbonate sols via vigorous agitation consisted of larger particles (on the order of $1 \mathrm{~mm}$; Figure 5a) than those obtained from acetone (on the order of a few hundred microns or smaller; Figure 5b). Aerogel powders were characterized in comparison to corresponding monolithic aerogels in terms of skeletal and bulk densities and BET surface areas (determined with $\mathrm{N}_{2}$-sorption porosimetry; Table 1). The skeletal densities were in general somewhat higher for samples prepared in propylene carbonate. The BET surface areas were consistently 2-3 times higher in powders prepared in acetone versus powders prepared in propylene carbonate (Table 1). Average pore diameters in the range of $1.7-300 \mathrm{~nm}$ were all in the range of 10-30 nm for all powders. Compared to monoliths with the same monomer concentration, powders had almost identical bulk and skeletal densities, and slightly lower BET surface areas (e.g., 162 versus $222 \mathrm{~m}^{2} \mathrm{~g}^{-1}$ for monomer concentration $5.5 \% \mathrm{w} / \mathrm{w}$ ). It is interesting that the tapped densities of PUA powders (Table 2) increased with increasing concentration of Desmodur N3300 in the sol. The fact that the tapped densities of PUA powders varied with the monomer concentration in the sol signifies that vigorous agitation disrupts gelation at some higher aggregate level, beyond primary and secondary particles. As noted experimentally, even larger aggregates seem to coagulate with one another upon standing into larger chunks upon standing.
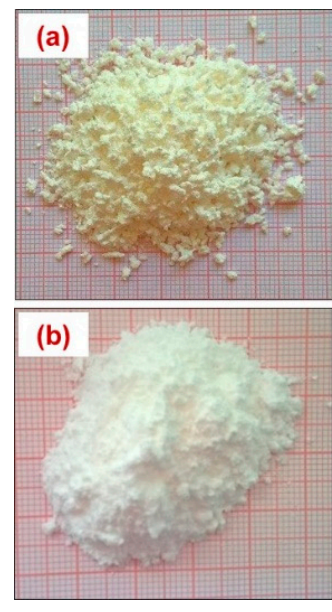
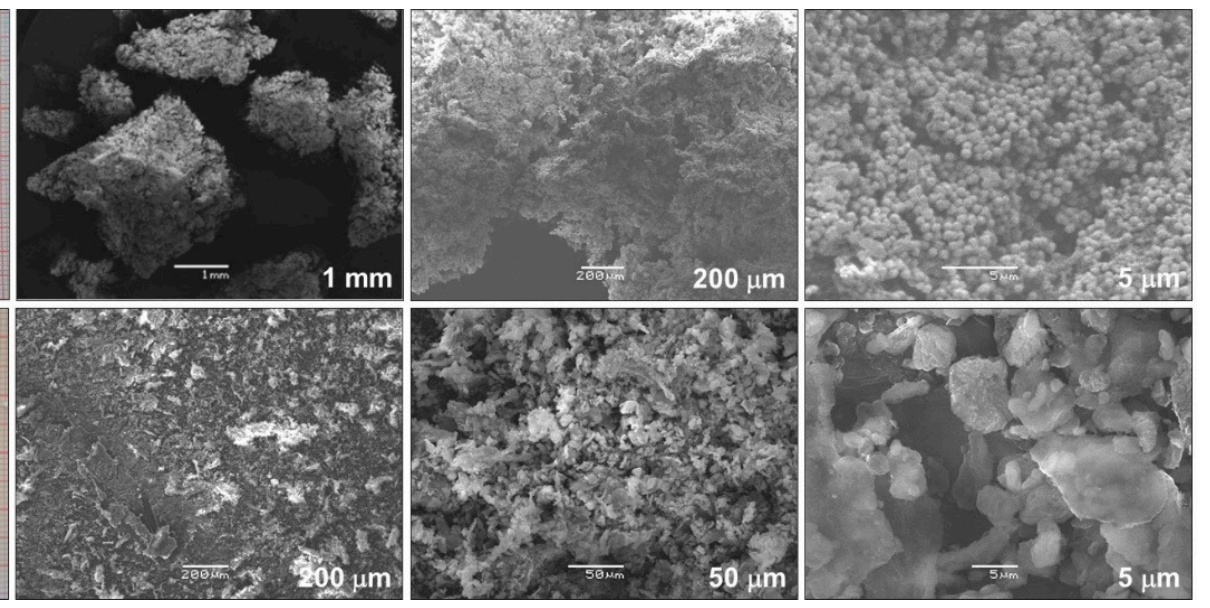

Figure 5. Photographs and SEM images at different magnifications of PUA powders prepared from Desmodur N3300 and water in propylene carbonate (a) or acetone (b) via vigorous agitation of the sol (monomer concentration: $5.5 \% \mathrm{w} / \mathrm{w}$ ). Scale lengths are indicated in the right-bottom corner of each frame.

Powders were also obtained via suspension polymerization in propylene carbonate/hexane mixtures (volume ratio $=1: 3$ ). In terms of particle shape and size, suspension polymerization versus vigorous agitation gave remarkably different results: sols with low monomer concentration $(5.5 \%$ 
$\mathrm{w} / \mathrm{w}$ ) under suspension polymerization gave much smaller particles ( $<500$ microns) relative to simple vigorous agitation that gave mm-size particles (Figure 5). Higher monomer concentration sols (11\% $\mathrm{w} / \mathrm{w}$ ) under suspension polymerization gave more-or-less uniform spherical particles, about $120 \mu \mathrm{m}$ in diameter (Figure 6). Under higher magnification (Figure 6) the large spherical particles consisted of micron-size spherical knots, connected with fibers. Based on the fact that the BET surface area of those samples was lower than the BET surface area of the lower concentration samples (97 versus $140 \mathrm{~m}^{2} \mathrm{~g}^{-1}$; Table 1), it is presumed that the spherical knots shown in Figure 6 did not have an internal structure. Average pore diameters in the range of 1.7-300 $\mathrm{nm}$ were in the range of 20-30 nm for all powders. The skeletal (Table 1) and tapped (Table 2) densities of samples prepared via this method were similar to those obtained via the vigorous agitation method. The BET surface area of the lower concentration sample via suspension polymerization was about 3 times higher $\left(\mathrm{m}^{2} \mathrm{~g}^{-1}\right)$ than the BET surface area of the sample via simple vigorous agitation (140 versus $52 \mathrm{~m}^{2} \mathrm{~g}^{-1}$; Table 1$)$.
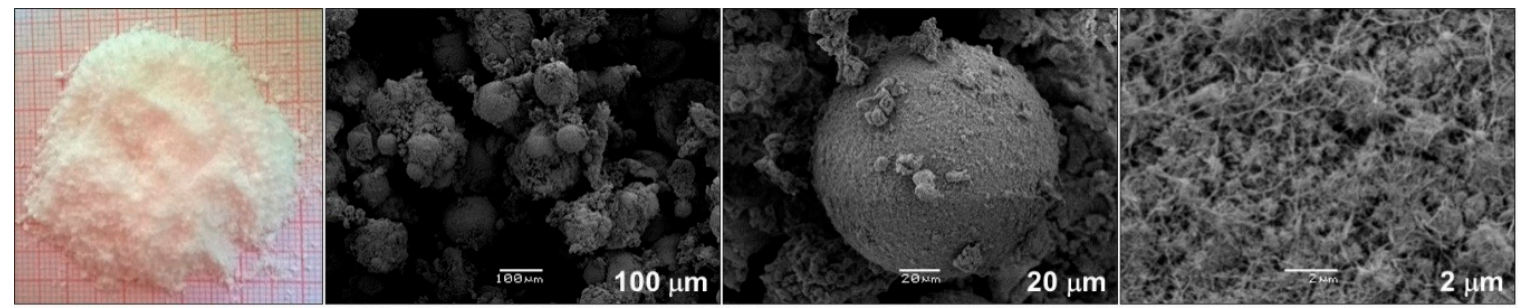

Figure 6. Photograph and SEM images at different magnifications of PUA powder prepared from Desmodur N3300 and water in propylene carbonate/hexane via suspension polymerization (monomer concentration: $11 \% \mathrm{w} / \mathrm{w}$ ). Scale lengths are indicated in the right-bottom corner of each frame.

The use of surfactant in powder formation was studied using two types of surfactants: CTAB (cetyltrimethylammonium bromide; Scheme 4) and NIKKOL BL-9EX (polyoxyethylene alkyl ether of lauryl alcohol; Scheme 4), at two different concentrations each: $0.7 \%$ and $3.5 \% \mathrm{w} / \mathrm{w}$ relative to the continuous phase. The use of CTAB as surfactant in sols with monomer concentration $5.5 \% \mathrm{w} / \mathrm{w}$ resulted in PUA powders of lower bulk (and tapped) density, compared with PUA samples obtained via vigorous agitation or suspension polymerization (Table 1). On the other hand, skeletal densities of all samples were almost identical (Table 1$)$. The BET surface area was higher when the low $(0.7 \% \mathrm{w} / \mathrm{w})$ concentration of surfactant was used, while higher concentration $(3.5 \% \mathrm{w} / \mathrm{w})$ of surfactant provided the same value of BET surface area as suspension polymerization. The use of CTAB in sols with higher monomer concentrations $(11 \% \mathrm{w} / \mathrm{w})$ did not show any improvement in terms of densities and BET surface areas, compared to suspension polymerization (Table 1). The use of NIKKOL BL-9EX as surfactant did not affect the values of bulk and tapped density of PUA powders obtained with low monomer concertation $(5.5 \% \mathrm{w} / \mathrm{w})$, but PUA powders obtained with higher monomer concertation $(11 \%$ $\mathrm{w} / \mathrm{w}$ ) were more dense than powders obtained via suspension polymerization (Table 1). The highest BET surface area $\left(197 \mathrm{~m}^{2} \mathrm{~g}^{-1}\right.$; Table 1$)$ was measured with high surfactant concentration and low monomer concentration. The use of NIKKOL BL-9EX at higher monomer concentration sols did not show any improvement in terms of BET surface areas compared to suspension polymerization; the same observation was also made for CTAB. In terms of particle shape and size, in the presence of CTAB low monomer concentration sols gave similar particles (Figure 7a) to those obtained via suspension polymerization, while high monomer concentration sols gave bigger (on the order of $1 \mathrm{~mm}$ ) and less uniform particles. At very low monomer concentration $(2.75 \% \mathrm{w} / \mathrm{w})$ most of the particles were spherical, but they could not be separated ( Figure $7 \mathrm{~b}-\mathrm{c}$ ). In the case of NIKKOL BL-9EX, powder morphology depended on the concentration of the monomer. At lower concentrations powders were fine, smooth and fluffy, whilst at higher concentrations powders were more granular (Figure 7d). Average pore diameters in the range of 1.7-300 $\mathrm{nm}$ were on the order of 20-30 $\mathrm{nm}$ for all powders. Some recipes started showing spherical particles, but they were neither uniform nor could they be separated. 


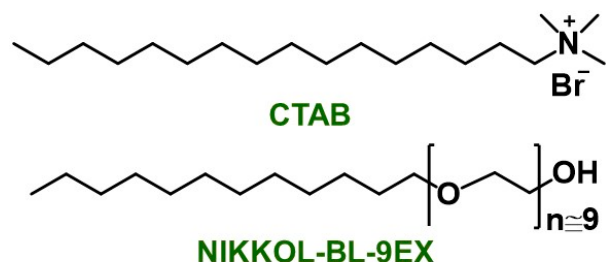

Scheme 4. Structures of surfactants CTAB and NIKKOL BL-9EX.
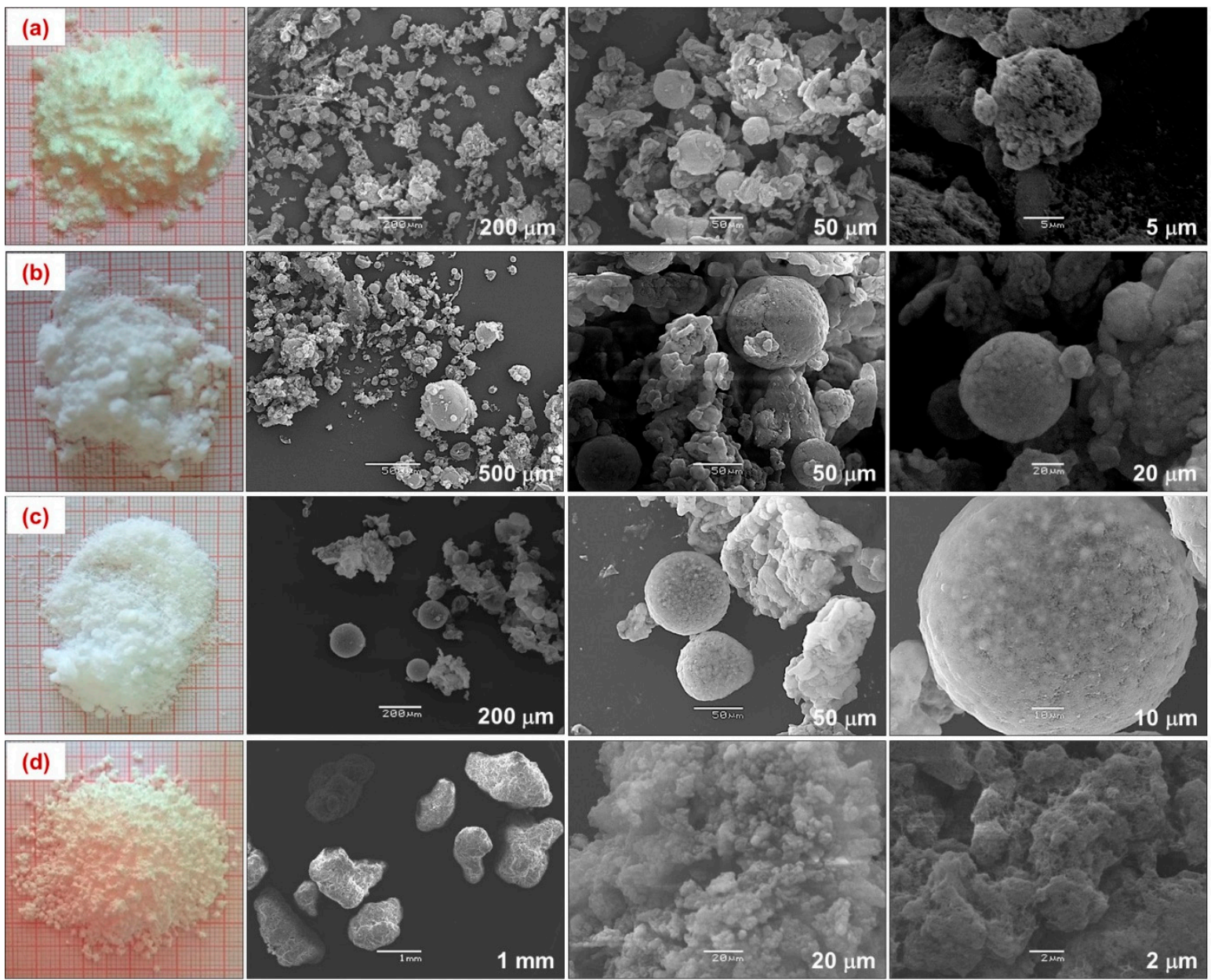

Figure 7. Photographs and SEM images at different magnifications of PUA powders prepared from Desmodur N3300 in propylene carbonate/hexane via emulsion polymerization. (a) CTAB 3.5\% w/w; monomer concentration: $5.5 \% \mathrm{w} / \mathrm{w}$. (b) CTAB $0.7 \% \mathrm{w} / \mathrm{w}$; monomer concentration: $2.75 \% \mathrm{w} / \mathrm{w}$. (c) CTAB 3.5\% w/w; monomer concentration: $2.75 \% \mathrm{w} / \mathrm{w}$. (d) NIKKOL BL-9EX 0.7\% w/w; monomer concentration: $11 \% \mathrm{w} / \mathrm{w}$. Scale lengths are indicated in the right-bottom corner of each frame.

PUA aerogel granules were also obtained from the reaction of aromatic Desmodur RE (Scheme 2) with water in DMF, and in the mixtures DMF/hexane and propylene carbonate/hexane (volume ratio $=1: 3$ ), using the experimental setup shown in Figure 4. The synthetic procedures are described in the Supplementary Material section. Formulations and gelation times are reported in Table S5.

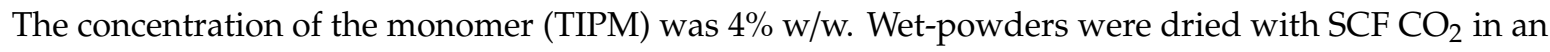
autoclave to provide aerogel powders, which consisted of irregular granules. Desmodur RE was used as received, i.e., $27 \% \mathrm{w} / \mathrm{w}$ solution of TIPM in ethyl acetate. Ethyl acetate played the role of a third solvent that rendered DMF and PC miscible with hexane. DMF/hexane, and PC/hexane mixtures here were single-systems, thereby the role of hexane was to: (a) dilute the sol; (b) decrease the solubility of the growing polymer; and, (c) induce early phase-separation of smaller particles. Thus, all powders 
from Desmodur RE can be classified as products of precipitation polymerization, which therefore may be considered as a variant of vigorous agitation. Aerogel powders were characterized in comparison to the corresponding monolithic aerogels in terms of skeletal density and BET surface areas (determined with $\mathrm{N}_{2}$-sorption porosimetry; Table 1). Bulk densities could not be measured accurately, because the materials consisted of relatively large particles of irregular shape and size. Powders obtained from DMF consisted of chunks and coarse powder Figure 8a), while those obtained from DMF/hexane were more even, consisting of particles of a more uniform size (on the order of $1 \mathrm{~mm}$ ) and shape (Figure 8b). Powders obtained from PC/hexane consisted of bigger particles. The skeletal densities of PUA powders prepared in DMF or DMF/hexane were almost identical and very similar with the skeletal density of the monoliths (Table 1). In propylene carbonate/hexane the skeletal density was slightly higher. The BET surface areas were higher when hexane was used; the highest value was obtained in propylene carbonate/hexane $\left(481 \mathrm{~m}^{2} \mathrm{~g}^{-1}\right.$; Table 1$)$. In all samples a $15-38 \%$ of the total surface area was assigned to micropores (Table 1), which in turn was attributed to the rigid structure of the aromatic triisocyanate-in accord with previous observations in similar materials $[81,82,92]$. Average pore diameters in the range of 1.7-300 nm were all found between $10 \mathrm{~nm}$ and $30 \mathrm{~nm}$ for all powders, and followed the same trend with the values obtained for the BET surface areas.
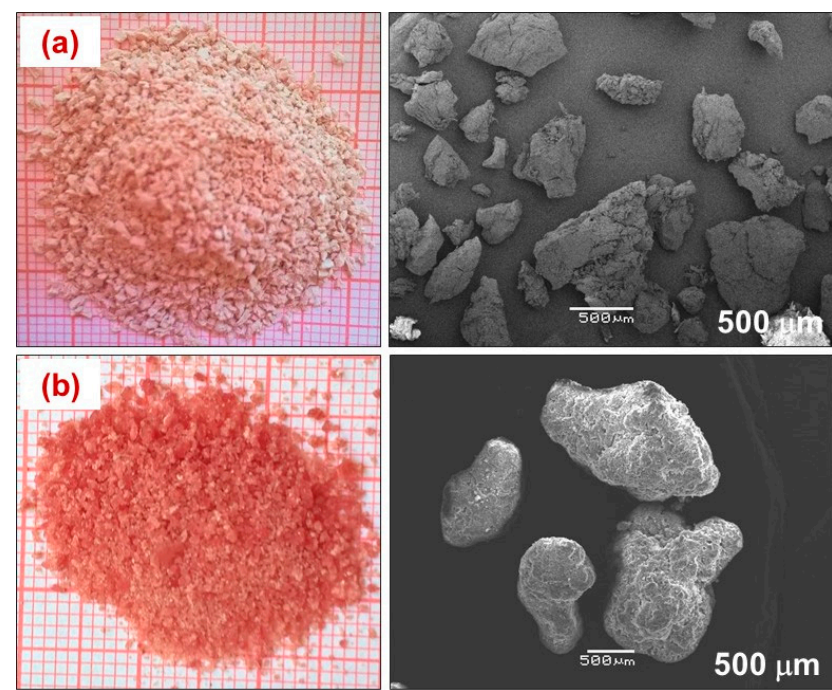
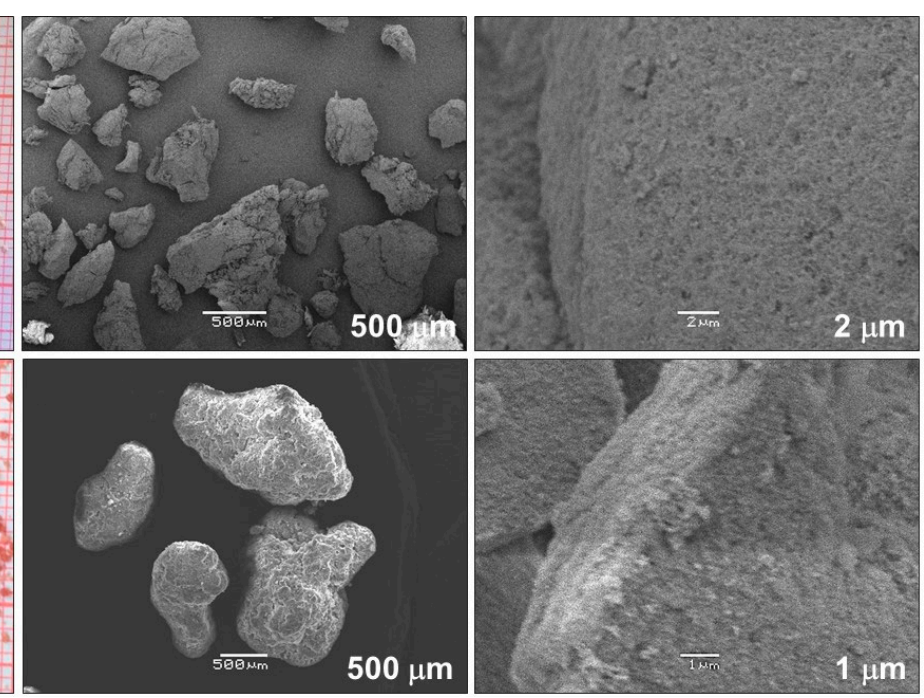

Figure 8. Photographs and SEM images at different magnifications of PUA powders prepared from Desmodur RE (monomer concentration: $4 \% \mathrm{w} / \mathrm{w}$ ) and water in: (a) DMF via vigorous agitation of the sol and (b) DMF/hexane via precipitation polymerization. Scale lengths are indicated in the right-bottom corner of each frame.

Owing to the irregular shape of the particles, the flow characteristics of the powders were assessed by calculating the percent compressibility index $\left(100\left(\rho_{\mathrm{t}}-\rho_{\mathrm{b}}\right) / \rho_{\mathrm{t}}\right)$ and the Hausner ratio $\left(\rho_{\mathrm{t}} / \rho_{\mathrm{b}}\right.$; Table 2$)$, from bulk $\left(\rho_{\mathrm{b}}\right)$ and tapped $\left(\rho_{\mathrm{t}}\right)$ density data [93]. The flow characteristics of powders are classified as excellent, good, fair, passable, poor and very poor, for compressibility index values (\%) in the range of $1-10,11-15,16-20,21-25,26-31$ and 32-37, or Hausner ratio values in the range of 1.00-1.11, 1.12-1.18, $1.19-1.25,1.26-1.34,1.35-1.45$ and 1.46-1.59, respectively. Overall, according to those methods the flow characteristics of most PUA aerogel powders were classified as passable, poor or very poor, except for three samples: (a) PUA powder synthesized from Desmodur RE and water in DMF/hexane showed fair flow characteristics; (b) PUA powder synthesized from Desmodur N3300 and water (monomer concentration: $11 \% \mathrm{w} / \mathrm{w}$ ) in propylene carbonate/hexane with NIKKOL BL-9EX $(0.7 \% \mathrm{w} / \mathrm{w})$ showed good flow characteristics; and, (c) PUA powder synthesized from Desmodur N3300 and water (monomer concentration: $2.75 \% \mathrm{w} / \mathrm{w}$ ) in propylene carbonate/hexane with CTAB $(3.5 \% \mathrm{w} / \mathrm{w})$ showed excellent flow characteristics. 


\subsection{PUA Aerogel Spherical Beads}

Spherical PUA beads were synthesized from the reaction of Desmodur N3300 (Scheme 2) (in propylene carbonate) and ethylene diamine (Scheme 3) in heavy mineral oil, via the dripping method at r.t. and SCF drying. The synthetic method is simple, cost-efficient and suitable for large-scale production of PUA aerogel beads. The beads (Figure 9) can be $2-4 \mathrm{~mm}$ in diameter with narrow size distributions (full width at half maximum: $0.3-0.4 \mathrm{~mm}$ ) and they have low density $\left(0.16 \mathrm{~g} \mathrm{~cm}^{-3}\right)$, high porosity $(>87 \% \mathrm{v} / \mathrm{v})$, and high surface area $\left(200 \mathrm{~m}^{2} \mathrm{~g}^{-1}\right)$. Analogous monoliths had similar density and porosity, but much lower surface area $\left(70 \mathrm{~m}^{2} \mathrm{~g}^{-1}\right)$. To our knowledge this work comprises the first-time report of uniform, millimeter-size PUA particles via a method that can be easily applied for large-scale production. The material properties of those beads were similar to those of chemically related and morphologically similar monoliths reported in the literature [67] from the reaction of the same triisocyanate with water in acetone, suggesting that nanostructure rather than minor differences in chemical composition is the property-determining factor. SEM (Figure 10) showed that the surface of the beads had a different morphology from their interior, which may be explained by the diffusion profile of ethylenediamine in the propylene carbonate droplets [94]. The water contact angle in the interior of the beads (by sanding) was about $102^{\circ}$. Dividing that value by the porosity of the beads gave a ratio of about 1.2. That ratio is referred to as the K-index, which was introduced recently as a means to quantify nanomorphology [91]. The development of the $K$-index was based on a vast array of monolithic polyurea aerogels, and therefore it applies directly to the nanomorphology of the PUA beads. High aspect ratio (caterpillar-like) nanostructures are expected to have $K$-index $=1.2$, in agreement with both the SEM of PUA beads (Figure 10) and the ratio of the experimental contact angle of water droplets $\left(102^{\circ}\right)$ over the porosity of the beads $(87 \% \mathrm{v} / \mathrm{v})$.
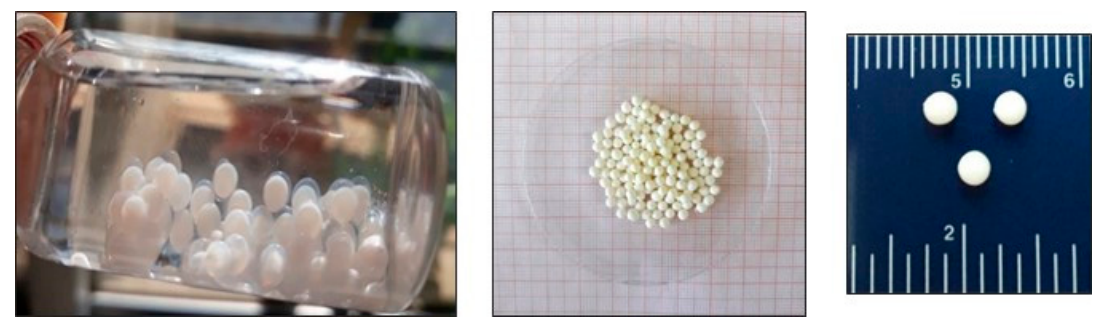

Figure 9. Photographs of PUA aerogel beads (wet-gels and aerogels) [94].

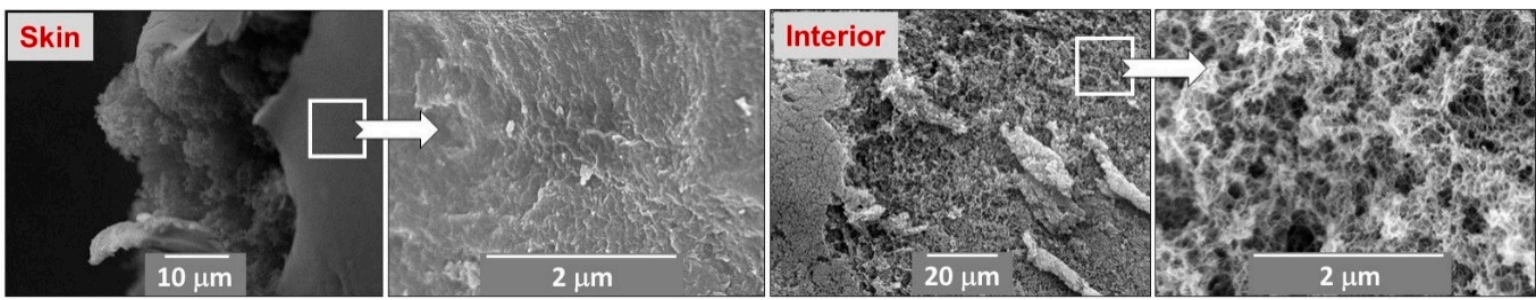

Figure 10. SEM images of spherical PUA aerogel beads at different magnifications: skin and interior, as indicated [94]. 
Table 1. Selected properties of particulate PUA aerogels.

\begin{tabular}{|c|c|c|c|c|c|c|c|c|c|}
\hline \multirow[t]{2}{*}{$\begin{array}{l}\text { Sample } \\
\text { I.D. }\end{array}$} & \multirow[t]{2}{*}{$\begin{array}{l}\text { Particle } \\
\text { Diameter }\end{array}$} & \multicolumn{2}{|c|}{$\begin{array}{l}\text { Bulk Density } \\
\rho_{\mathrm{b}}\left(\mathrm{g} \mathrm{cm}^{-3}\right)\end{array}$} & \multicolumn{2}{|c|}{$\begin{array}{l}\text { Skeletal Density } \\
\qquad \rho_{\mathrm{s}}\left(\mathrm{g} \mathrm{cm}^{-3}\right)\end{array}$} & \multicolumn{2}{|c|}{$\begin{array}{c}\text { BET Surf. Area } \\
\sigma\left(\mathrm{m}^{2} \mathrm{~g}^{-1}\right) \\
\text { [Micropore Surf. Area] }^{\mathrm{a}}\end{array}$} & \multicolumn{2}{|c|}{$\begin{array}{l}\text { Particle Radius } \\
\text { (nm) }\end{array}$} \\
\hline & & Particle & Monolith & Particle & Monolith & Particle & Monolith & Particle & Monolith \\
\hline $\mathrm{N} 3300-\mathrm{H}_{2} \mathrm{O} 2.75 \%$ acetone & $<20 \mu \mathrm{m}$ & $0.023 \pm 0.001$ & $0.028 \pm 0.002$ & $1.35 \pm 0.02$ & $1.31 \pm 0.06$ & $162 \pm 9$ & $159 \pm 8$ & $13.7 \pm 0.8$ & $14.4 \pm 1.0$ \\
\hline $\mathrm{N} 3300-\mathrm{H}_{2} \mathrm{O} 5.5 \%$ acetone & $<20 \mu \mathrm{m}$ & $0.048 \pm 0.001$ & $0.07 \pm 0.01$ & $1.182 \pm 0.006$ & $1.20 \pm 0.01$ & $162 \pm 8$ & $222 \pm 13$ & $15.7 \pm 0.8$ & $11.3 \pm 0.7$ \\
\hline $\mathrm{N} 3300-\mathrm{H}_{2} \mathrm{O} 11 \%$ acetone & $<50 \mu \mathrm{m}$ & $0.113 \pm 0.008$ & $0.126 \pm 0.001$ & $1.166 \pm 0.007$ & $1.19 \pm 0.01$ & $113 \pm 7$ & $165 \pm 9$ & $22.8 \pm 1.4$ & $15.3 \pm 0.8$ \\
\hline $\mathrm{N} 3300-\mathrm{H}_{2} \mathrm{O} 2.75 \%$ PC & $1-2 \mathrm{~mm}$ & $0.036 \pm 0.001$ & c & $1.39 \pm 0.03$ & c & $95 \pm 5$ & c & $22.7 \pm 1.3$ & c \\
\hline $\mathrm{N} 3300-\mathrm{H}_{2} \mathrm{O} 5.5 \%$ PC & $1-2 \mathrm{~mm}$ & $0.058 \pm 0.001$ & c & $1.37 \pm 0.03$ & c & $52 \pm 3$ & c & $42.1 \pm 2.6$ & c \\
\hline $\mathrm{N} 3300-\mathrm{H}_{2} \mathrm{O} 11 \%$ PC & - & d & c & d & c & $\mathrm{d}$ & c & $d$ & c \\
\hline $\mathrm{N} 3300-\mathrm{H}_{2} \mathrm{O} 5.5 \%$ PC/hexane & $<500 \mu \mathrm{m}$ & $0.060 \pm 0.001$ & & $1.36 \pm 0.03$ & & $140 \pm 7$ & & $15.8 \pm 0.9$ & \\
\hline $\mathrm{N} 3300-\mathrm{H}_{2} \mathrm{O} 11 \%$ PC/hexane & $120 \mu \mathrm{m}$ & $0.034 \pm 0.001$ & & $1.29 \pm 0.02$ & & $97 \pm 6$ & & $24.0 \pm 1.5$ & \\
\hline $\mathrm{N} 3300-\mathrm{H}_{2} \mathrm{O} 2.75 \%$ CTAB $0.7 \%$ & $<200 \mu \mathrm{m}$ & $0.045 \pm 0.003$ & & $1.24 \pm 0.01$ & & $141 \pm 8$ & & $17.2 \pm 1.0$ & \\
\hline $\mathrm{N} 3300-\mathrm{H}_{2} \mathrm{O} 5.5 \%$ CTAB $0.7 \%$ & $100-200 \mu \mathrm{m}$ & $0.025 \pm 0.002$ & & $1.38 \pm 0.04$ & & $174 \pm 10$ & & $12.5 \pm 0.8$ & \\
\hline $\mathrm{N} 3300-\mathrm{H}_{2} \mathrm{O} 11 \%$ CTAB $0.7 \%$ & $\sim 1 \mathrm{~mm}$ & $0.033 \pm 0.001$ & & $1.32 \pm 0.02$ & & $80 \pm 4$ & & $28.4 \pm 1.5$ & \\
\hline $\mathrm{N} 3300-\mathrm{H}_{2} \mathrm{O} 2.75 \%$ CTAB 3.5\% & $<200 \mu \mathrm{m}$ & $0.057 \pm 0.001$ & & $1.29 \pm 0.01$ & & $162 \pm 9$ & & $14.4 \pm 0.8$ & \\
\hline $\mathrm{N} 3300-\mathrm{H}_{2} \mathrm{O} 5.5 \%$ CTAB 3.5\% & $200-250 \mu \mathrm{m}$ & $0.038 \pm 0.003$ & & $1.28 \pm 0.01$ & & $144 \pm 8$ & & $16.3 \pm 0.9$ & \\
\hline N3300- $\mathrm{H}_{2} \mathrm{O} 11 \%$ CTAB 3.5\% & $\sim 1 \mathrm{~mm}$ & $0.035 \pm 0.002$ & & $1.29 \pm 0.01$ & & $51 \pm 3$ & & $45.6 \pm 2.7$ & \\
\hline N3300- $\mathrm{H}_{2} \mathrm{O} 5.5 \%$ NIKKOL BL-9EX 0.7\% & $<100 \mu \mathrm{m}$ & $0.078 \pm 0.002$ & & $1.66 \pm 0.08$ & & $4 \pm 1$ & & $452 \pm 115$ & \\
\hline N3300- $\mathrm{H}_{2} \mathrm{O} 11 \%$ NIKKOL BL-9EX 0.7\% & $\sim 1 \mathrm{~mm}$ & $0.094 \pm 0.001$ & & $1.41 \pm 0.03$ & & $85 \pm 5$ & & $25.0 \pm 1.6$ & \\
\hline N3300- $\mathrm{H}_{2} \mathrm{O} 5.5 \%$ NIKKOL BL-9EX 3.5\% & $\sim 100 \mu \mathrm{m}$ & $0.052 \pm 0.003$ & & $1.47 \pm 0.06$ & & $197 \pm 11$ & & $10.4 \pm 0.7$ & \\
\hline N3300- $\mathrm{H}_{2} \mathrm{O} 11 \%$ NIKKOL BL-9EX 3.5\% & $0.5-1 \mathrm{~mm}$ & $0.077 \pm 0.001$ & & $1.50 \pm 0.07$ & & $76 \pm 4$ & & $26.3 \pm 1.9$ & \\
\hline $\mathrm{RE}-\mathrm{H}_{2} \mathrm{O} 4 \% \mathrm{DMF}$ & $\sim 500 \mu \mathrm{m}$ & e & $0.393 \pm 0.033$ & $1.254 \pm 0.001$ & $1.353 \pm 0.009$ & $215 \pm 12[15]$ & $205 \pm 11[20]$ & $11.1 \pm 0.6$ & $10.8 \pm 0.6$ \\
\hline RE- $\mathrm{H}_{2} \mathrm{O} 4 \%$ DMF/hexane & $\sim 1 \mathrm{~mm}$ & $0.30 \pm 0.01$ & & $1.264 \pm 0.001$ & & $394 \pm 21[43]$ & & $6.0 \pm 0.3$ & \\
\hline RE- $\mathrm{H}_{2} \mathrm{O} 4 \%$ PC/hexane & $\sim 1 \mathrm{~mm}$ & e & & $1.324 \pm 0.008$ & & $481 \pm 24[22]$ & & $4.7 \pm 0.2$ & \\
\hline N3300-EDA 11\% [94] & $2.68 \pm 0.16 \mathrm{~mm}$ & $0.166 \pm 0.001$ & $0.110 \pm 0.001$ & $1.246 \pm 0.005$ & $1.236 \pm 0.006$ & $197 \pm 12$ & $73 \pm 4$ & $12.2 \pm 0.7$ & $33.2 \pm 1.8$ \\
\hline
\end{tabular}

${ }^{\mathrm{a}}$ Micropore surface area via $t$-plot analysis, according to the Harkins and Jura. ${ }^{\mathrm{b}}$ Calculated via: $r=3 /\left(\rho_{\mathrm{s}} \times \sigma\right) .{ }^{\mathrm{c}}$ Monoliths of irregular shape. ${ }^{\mathrm{d}}$ Owing to fast reaction the entire sol gelled and subsequently the gel was broken by the mechanical stirrer into large monolithic pieces. ${ }^{\mathrm{e}}$ Small amount of powder, not sufficient for this measurement. Most of the sample was in the form of large chunks and lumps. PC: propylene carbonate. 
Table 2. Flow characteristics of particulate PUA aerogels.

\begin{tabular}{|c|c|c|c|c|c|}
\hline $\begin{array}{c}\text { Sample } \\
\text { I.D. }\end{array}$ & $\begin{array}{c}\text { Bulk Density } \\
\rho_{\mathrm{b}}\left(\mathrm{g} \mathrm{cm}^{-3}\right)\end{array}$ & $\begin{array}{c}\text { Tapped Density } \\
\rho_{\mathrm{t}}\left(\mathrm{g} \mathrm{cm}^{-3}\right)\end{array}$ & $\begin{array}{c}\text { Compressibility } \\
\text { Index }^{\text {a }}\end{array}$ & $\begin{array}{c}\text { Hausner } \\
\text { Ratio }^{b}\end{array}$ & Flow Quality \\
\hline $\mathrm{N} 3300-\mathrm{H}_{2} \mathrm{O} 2.75 \%$ acetone & $0.023 \pm 0.001$ & $0.036 \pm 0.001$ & 36 & 1.57 & very poor \\
\hline $\mathrm{N} 3300-\mathrm{H}_{2} \mathrm{O} 5.5 \%$ acetone & $0.048 \pm 0.001$ & $0.063 \pm 0.005$ & 24 & 1.31 & passable \\
\hline $\mathrm{N} 3300-\mathrm{H}_{2} \mathrm{O} 11 \%$ acetone & $0.113 \pm 0.008$ & $0.166 \pm 0.008$ & 32 & 1.47 & very poor \\
\hline $\mathrm{N} 3300-\mathrm{H}_{2} \mathrm{O} 2.75 \%$ PC & $0.036 \pm 0.001$ & $0.047 \pm 0.001$ & 23 & 1.31 & passable \\
\hline $\mathrm{N} 3300-\mathrm{H}_{2} \mathrm{O} 5.5 \%$ PC & $0.058 \pm 0.001$ & $0.078 \pm 0.002$ & 26 & 1.34 & passable \\
\hline $\mathrm{N} 3300-\mathrm{H}_{2} \mathrm{O} 5.5 \%$ PC/hexane & $0.060 \pm 0.001$ & $0.078 \pm 0.001$ & 23 & 1.30 & passable \\
\hline N3300- $\mathrm{H}_{2} \mathrm{O} 11 \%$ PC/hexane & $0.034 \pm 0.001$ & $0.050 \pm 0.001$ & 32 & 1.47 & very poor \\
\hline $\mathrm{N} 3300-\mathrm{H}_{2} \mathrm{O} 2.75 \%$ CTAB 0.7\% & $0.045 \pm 0.003$ & $0.068 \pm 0.001$ & 34 & 1.51 & very poor \\
\hline $\mathrm{N} 3300-\mathrm{H}_{2} \mathrm{O} 5.5 \%$ CTAB $0.7 \%$ & $0.025 \pm 0.002$ & $0.038 \pm 0.001$ & 34 & 1.52 & very poor \\
\hline $\mathrm{N} 3300-\mathrm{H}_{2} \mathrm{O} 11 \%$ CTAB $0.7 \%$ & $0.033 \pm 0.001$ & $0.045 \pm 0.001$ & 27 & 1.36 & poor \\
\hline $\mathrm{N} 3300-\mathrm{H}_{2} \mathrm{O} 2.75 \%$ CTAB 3.5\% & $0.057 \pm 0.001$ & $0.059 \pm 0.002$ & 3 & 1.04 & excellent \\
\hline $\mathrm{N} 3300-\mathrm{H}_{2} \mathrm{O} 5.5 \%$ CTAB 3.5\% & $0.038 \pm 0.003$ & $0.059 \pm 0.005$ & 36 & 1.55 & very poor \\
\hline $\mathrm{N} 3300-\mathrm{H}_{2} \mathrm{O} 11 \%$ CTAB $3.5 \%$ & $0.035 \pm 0.002$ & $0.050 \pm 0.003$ & 30 & 1.43 & poor \\
\hline $\mathrm{N} 3300-\mathrm{H}_{2} \mathrm{O} 5.5 \%$ NIKKOL BL-9EX 0.7\% & $0.078 \pm 0.002$ & $0.104 \pm 0.004$ & 25 & 1.33 & passable \\
\hline N3300- $\mathrm{H}_{2} \mathrm{O} 11 \%$ NIKKOL BL-9EX 0.7\% & $0.094 \pm 0.001$ & $0.107 \pm 0.003$ & 12 & 1.14 & good \\
\hline N3300- $\mathrm{H}_{2} \mathrm{O} 5.5 \%$ NIKKOL BL-9EX 0.7\% & $0.052 \pm 0.003$ & $0.074 \pm 0.003$ & 30 & 1.42 & poor \\
\hline N3300- $\mathrm{H}_{2} \mathrm{O} 11 \%$ NIKKOL BL-9EX 0.7\% & $0.077 \pm 0.001$ & $0.097 \pm 0.002$ & 21 & 1.26 & passable \\
\hline RE- $\mathrm{H}_{2} \mathrm{O} 4 \%$ DMF/hexane & $0.30 \pm 0.01$ & $0.36 \pm 0.03$ & 17 & 1.20 & fair \\
\hline
\end{tabular}

${ }^{\mathrm{a}}$ Compressibility index: $100\left(\rho_{\mathrm{t}}-\rho_{\mathrm{b}}\right) / \rho_{\mathrm{t}} \cdot{ }^{\mathrm{b}}$ Hausner ratio: $\rho_{\mathrm{t}} / \rho_{\mathrm{b}} ; \rho_{\mathrm{b}}$ : bulk density, $\rho_{\mathrm{t}}$ : tapped density. 


\section{Polyimide (PI) Aerogels}

Polyimides (PI) are a class of engineering plastics, and are utilized for high temperature applications. PIs are synthesized commercially by two methods: (a) condensation $\left(>190^{\circ} \mathrm{C}\right)$ of aromatic dianhydrides and amines (the DuPont route; Scheme 5a) [95], and (b) crosslinking $\left(>300^{\circ} \mathrm{C}\right)$ of norbornene end-capped imide oligomers (referred to as the PMR route; PMR: polymerization of monomer reactants) $[96,97]$. PI aerogels based on the DuPont route were reported in a 2006 US patent [70]. An alternative method for the synthesis of PI aerogels was reported in 2010. That method was based on the reaction of aromatic dianhydrides with multifunctional isocyanates at room temperature [71,73] (Scheme 5b). Both the DuPont route and the isocyanate route yield chemically identical products. The main advantages of the isocyanate route are: the low cost of the isocyanates, no sacrificial reagents needed (versus acetic anhydride and pyridine by the DuPont route) needed, and the only byproduct is $\mathrm{CO}_{2}$ (versus $\mathrm{HCl}$ from the DuPont route). Detailed structural analysis with small angle neutron scattering (SANS) has revealed that materials synthesized in $\mathrm{N}$-methyl pyrrolidone (NMP) via either route consist of similar size primary and secondary particles; SEM, however, has shown that secondary particles assembled differently: into fibers in the isocyanate route, and into globular aggregates in the amine route [70].

(a)<smiles>O=c1oc(=O)c2cc3c(=O)oc(=O)c3cc12</smiles>
dianhydride (PMDA)

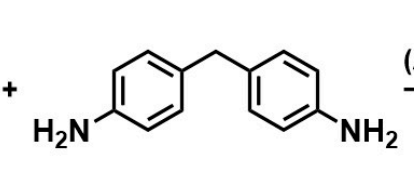
diamine (4,4'-MDA)

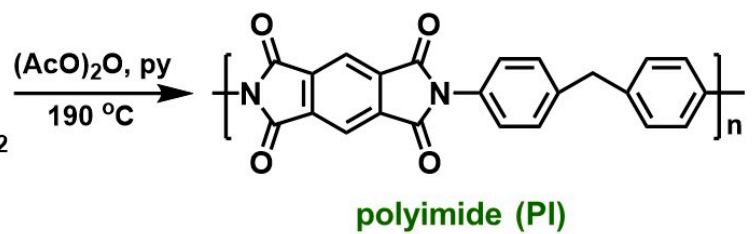

(b)

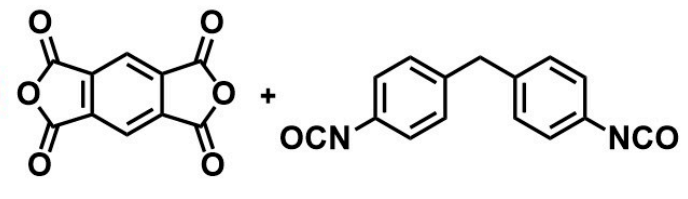
dianhydride (PMDA) diisocyanate (4,4'-MDI)

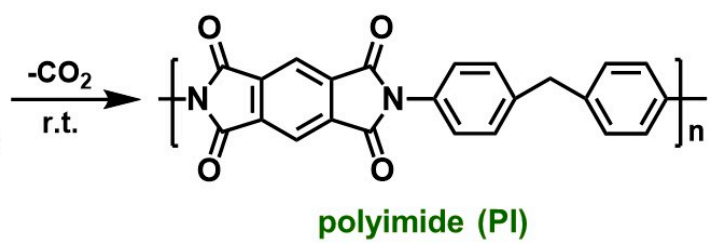

Scheme 5. Synthesis of chemically identical polyimide (PI) aerogels via two different routes: (a) from a dianhydride and a diamine (the DuPont route), (b) from the same dianhydride and the corresponding diisocyanate to the diamine of part (a). PMDA: pyromellitic dianhydride; $4,4^{\prime}$-MDA: 4,4'-diaminodiphenylmethane; and, 4,4'-MDI: 4,4'-methylenebis(phenyl isocyanate).

\subsection{Particulate PI Aerogels}

Nanofibrous PI powders (Figure 11) have been produced by mechanical agitation of a gel-like poly(amic acid) (PAA), which was obtained from pyromellitic dianhydride (PMDA; Scheme 5) and 4,4' -methylenedianiline (4,4'-MDA; Scheme 5) in THF/MeOH mixed solvent [98]. Interestingly, rather than a real gel (i.e., an elastic solid), the gel-like PAA product was a clear glass-like viscous solution that, upon addition of acetone, phase-separated into an opaque-white wet-gel. The authors pointed out that a gel-like PAA product was obtained only from the specific monomers; other starting materials yielded only viscous solutions of the corresponding PAAs. Subsequently, acetone was solvent-exchanged with cyclohexane, which was removed under vacuum at about $10{ }^{\circ} \mathrm{C}$ yielding PAA aerogels that were imidized by heating successively at 100,200 and finally at $300^{\circ} \mathrm{C}$. If addition of acetone into the gel-like PAA product was accompanied by vigorous mechanical stirring, the end product was an aerogel powder rather than a monolith. In contrast to the report of Kong et al. on PUA powders (see above) [90], vigorous agitation did not disrupt the microfibrous network structure of the PI, which was identical in both monoliths and powders. This new, green, scalable and economic process provided PI aerogel particles with nanofibrous morphology, low density $\left(0.175 \mathrm{~g} \mathrm{~cm}^{-1}\right)$ and high thermal stability. Their decomposition temperatures were above $500{ }^{\circ} \mathrm{C}$. 


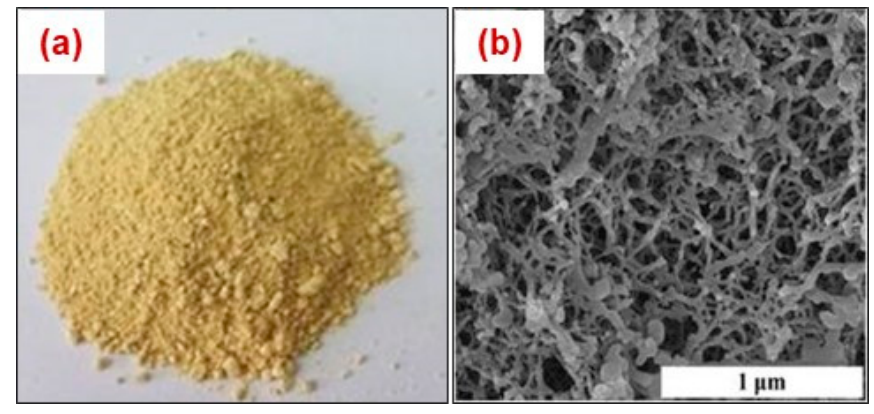

Figure 11. Photograph (a) and SEM image (b) of PI aerogel powders obtained from the imidization of PMDA/4,4'-MDA-derived PAA. Adapted by permission from Springer Nature Customer Service Centre GmbH: Ref. [98].

PI aerogel particles have been prepared in DMF/cyclohexane emulsions [54]. A solution consisting of PAA oligomers was prepared by dissolving PMDA and 2,2'-dimethylbenzidine (DMBZ; Scheme 3) in DMF at r.t. 1,3,5-Triaminophenoxybenzene (TAB; Scheme 3) was added to the sol, followed by drop-wise addition of acetic anhydride and pyridine. The resulting PI sol was dispersed in cyclohexane, using Span 85 and Hypermer 1599 as surfactants. The microparticles were washed with acetone and dried using SCF $\mathrm{CO}_{2}$. The resulting PI aerogel particles had mean diameters of $40.0 \mu \mathrm{m}$, pore volumes of $3.38 \mathrm{~cm}^{3} \mathrm{~g}^{-1}$, and a fibrous internal microstructure, similar to the one observed in the corresponding aerogel monoliths (Figure 12b). Their BET surface areas were lower than those of the monoliths (512 versus $717 \mathrm{~m}^{2} \mathrm{~g}^{-1}$ ), which was attributed to the shorter aging period.
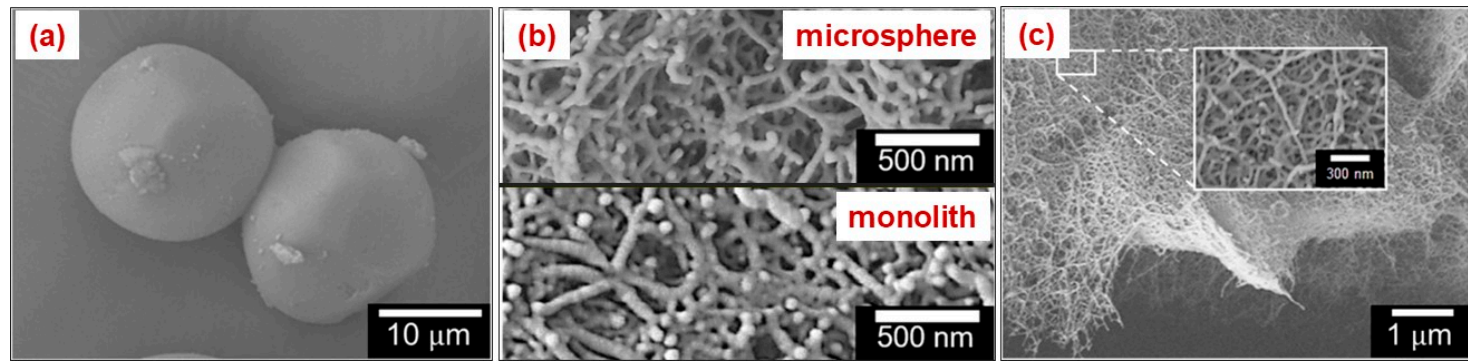

Figure 12. SEM images of: (a) PI aerogel microparticles, (b) their skeletal networks in comparison with corresponding monoliths, and (c) the surface of PI aerogel microparticles. Adapted with permission from Ref. [54]. Copyright 2016 American Chemical Society.

\subsection{PI Aerogel Spherical Beads}

Millimeter-size PI aerogel particles have been synthesized using the experimental setup shown in Figure 13 [99]. PAAs were synthesized via polymerization of PMDA and 4,4'-oxydianiline (4,4'-ODA; Scheme 3) in NMP, and were transformed to PI spherical microparticles by gradually heating the solution at $250{ }^{\circ} \mathrm{C}$ in an autoclave (Figure 13). Acetone was used to fill the space between the autoclave and the reaction vessel. Under the conditions of the reaction (temperature of $250{ }^{\circ} \mathrm{C}$ and pressure above $4.66 \mathrm{MPa}$ ), acetone is a supercritical fluid, and its high pressure prevented NMP from evaporating. The particles (Figure 14) were spherical with diameters ranging from 3.6 to $4.9 \mu \mathrm{m}$, BET surface areas of $103 \mathrm{~m}^{2} \mathrm{~g}^{-1}$, porosities of $80 \% \mathrm{v} / \mathrm{v}$, typical pore sizes at around $15 \mathrm{~nm}$ (Figure 14), and good thermal stability $\left(>500^{\circ} \mathrm{C}\right)$. Qualitatively, they also showed good oil adsorption capacity. Analogous PI aerogel monoliths reported were synthesized from PMDA and 4,4'-ODA, with 1,3,5-tris(4-aminophenyl)benzene (TAPB) as crosslinker, in NMP. Morphologically, the internal structure of those monoliths was more fibrous than the internal structure of spherical particles (Figure 15) [100]. 


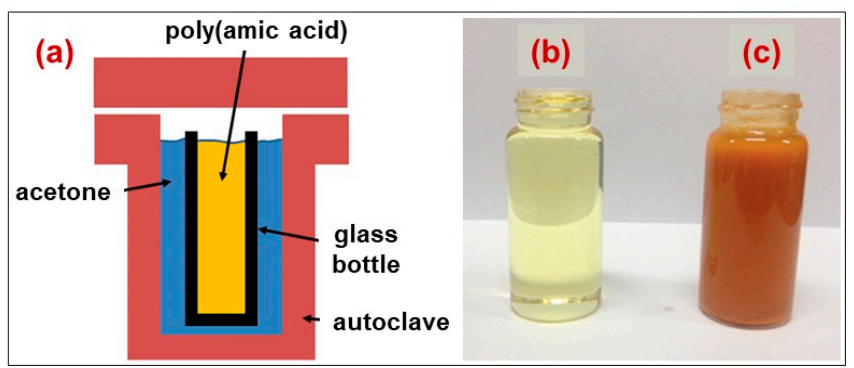

Figure 13. (a) Setup for the fabrication of PI aerogel microparticles. (b) Glass bottle with PAA before curing. (c) PI aerogel microparticles after curing. Copyright (2014) Wiley. Used with permission from Ref. [99].
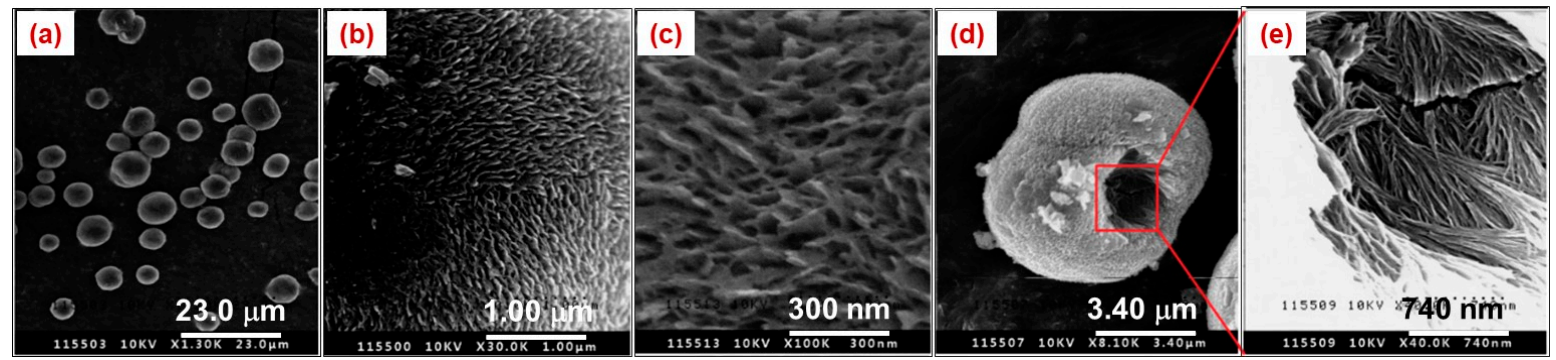

Figure 14. SEM images of: (a) PI aerogel microparticles; $(\mathbf{b}, \mathbf{c})$ their surfaces; $(\mathbf{d}, \mathbf{e})$ their interior. Copyright (2014) Wiley. Used with permission from Ref. [99].

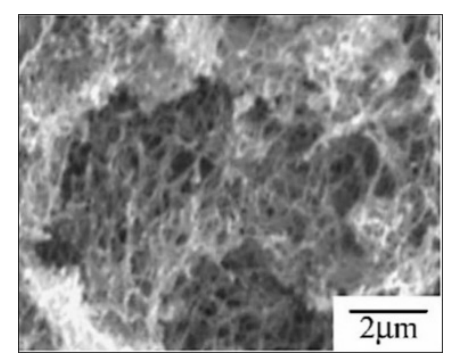

Figure 15. SEM image of the interior of a PI aerogel monolith derived from PMDA, 4, $4^{\prime}$-ODA and TAPB. Copyright (2007) Wiley. Used with permission from Ref. [100].

\section{Phenolic Resin Aerogels (Including Polybenzoxazines)}

Resorcinol-formaldehyde $(\mathrm{RF})$ aerogels and polybenzoxazine $(\mathrm{PBO})$ aerogels are the main carbon aerogel precursors $[14,56,58,60]$.

RF aerogels were first prepared in 1989 via base-catalyzed gelation of aqueous solutions of resorcinol and formaldehyde (up to 7 days at $85^{\circ} \mathrm{C}$ ), followed by aging ( $>3$ days in $\mathrm{CF}_{3} \mathrm{COOH}$ at $45^{\circ} \mathrm{C}$ ) and drying from $\mathrm{SCF} \mathrm{CO}_{2}[56-59]$. Acid-catalyzed processes have also been reported (Scheme 6) and include reactions in: (a) $\mathrm{HClO}_{4}$ /acetone at $45^{\circ} \mathrm{C}$ followed by 3 days of aging [101], (b) aqueous $\mathrm{HNO}_{3}$ at $80^{\circ} \mathrm{C}$ (2 day gelation, 7 days aging) [102], (c) acetic acid at room temperature (1 day gelation, aging for 3 days at $50{ }^{\circ} \mathrm{C}$ and 3 days at $90^{\circ} \mathrm{C}$ ) [103,104], and (d) $\mathrm{HCl} / \mathrm{CH}_{3} \mathrm{CN}$ at $80{ }^{\circ} \mathrm{C}$ (gelation within minutes, no aging) [55]. RF aerogels obtained by the acid-catalyzed routes are chemically similar to the ones obtained via the base-catalyzed aqueous gelation process. 


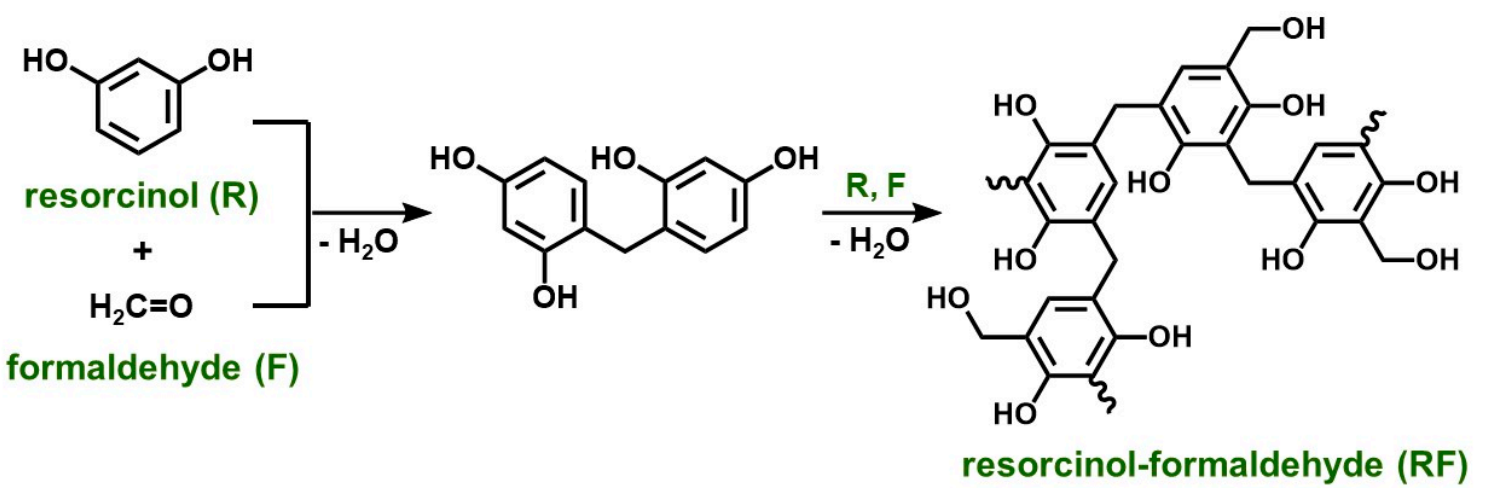

Scheme 6. Scheme 6. Synthesis of RF aerogels.

Polybenzoxazines (PBOs) are phenolic resins with high mechanical strength, inherent flame retardancy, low water retention, exceptional thermal properties (high glass transition and decomposition temperatures), and high carbonization yields [105]. Although benzoxazines were known since 1944 [106], the systematic study of their polymers began 50 years later [107]. PBOs are typically prepared via thermally induced ring-opening polymerization of suitable benzoxazine (BO) monomers, with most known the condensation product of bisphenol A, aniline, and formaldehyde (Scheme 7) [107-110]. Monolithic PBO aerogels have been synthesized via polymerization of that monomer in xylene at $130{ }^{\circ} \mathrm{C}$ for $96 \mathrm{~h}$ (heat-induced polymerization) [62,63], or in DMF at room temperature for a few hours (HCl-catalyzed polymerization) [64]. The HCl-catalyzed polymerization imposed additional crosslinking that resulted in higher surface areas and lower thermal conductivity.

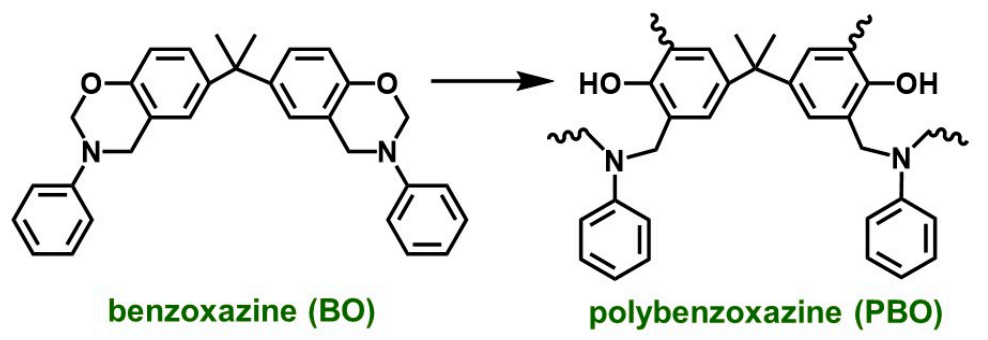

Scheme 7. Synthesis of $\mathrm{PBO}$ aerogels via polymerization of a $\mathrm{BO}$ monomer derived from the reaction of bisphenol A, aniline, and formaldehyde.

\subsection{RF Aerogel Beads}

RF aerogel spherical particles have been synthesized by various methods: (a) emulsion polymerization in water/cyclohexane, using $\mathrm{K}_{2} \mathrm{CO}_{3}$ as basic catalyst and a surfactant of the non-ionic sorbitan alkyl ester series by NOF Corp, followed by solvent exchange with acetone and drying from SCF CO 2 [48], (b) inverse suspension polymerization in water/peanut oil, with $\mathrm{Na}_{2} \mathrm{CO}_{3}$ as catalyst, followed by solvent exchange with alcohol and drying under alcohol supercritical conditions [49], and (c) an injection emulsification method, in which a syringe pump was used to inject droplets of an aqueous solution, containing resorcinol, formaldehyde and $\mathrm{Na}_{2} \mathrm{CO}_{3}$, into the continuous phase of cyclohexane, containing Span 80 as emulsifier, followed by solvent exchange with acetone and drying from $\mathrm{SCF} \mathrm{CO}_{2}$ [53]. However, in all those cases, the RF aerogel particles were not characterized, as the authors were more interested in the products of their pyrolysis.

$\mathrm{RF}$ aerogel foam beads, with diameter of $1 \mathrm{~mm}$ and a smooth membrane covering their surface (Figure 16) have been synthesized by dropwise addition of the aqueous resorcinol/formaldehyde/ $\mathrm{Na}_{2} \mathrm{CO}_{3}$ solution in a $\mathrm{CCl}_{4} /$ mineral oil mixture, which had equal density to the RF sol and also contained a basic phase-transfer catalyst (triethylamine or tri(n-butyl)amine) [111]. After the droplets gelled, they were solvent exchanged with 2-propanol and underwent SCF $\mathrm{CO}_{2}$ drying. Those aerogels had densities in the 
range of 104-184 $\mathrm{mg} \mathrm{cm}^{-3}$, increasing with decreased concentration of the catalyst and decreased length of its alkyl chain. The cell size of the foams (from SEM images) ranged from 55 to $93 \mathrm{~nm}$ when trimethylamine was used and from 40 to $46 \mathrm{~nm}$ when tri(n-butyl)amine was used; in both cases, cell sizes increased with the catalyst concentration. In analogy to what has been observed with PUA beads [94] (Figure 10), the morphology of the surface of the RF aerogel beads was smoother (especially when tri( $n$-butyl)amine was used as catalyst), while internally all RF beads had more or less the same structure (Figure 16).
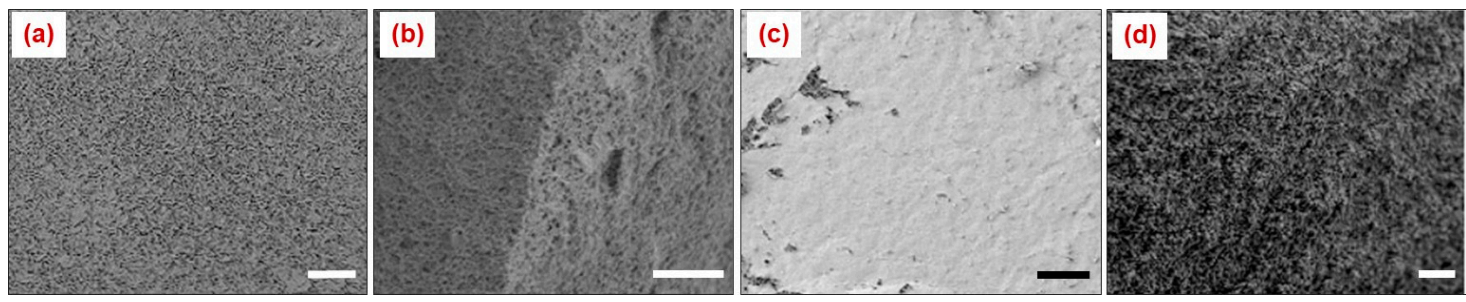

Figure 16. SEM images of outer surfaces $(\mathbf{a}, \mathbf{c})$ and inner surfaces of skins and bulk morphologies (b,d) of RF foam aerogel beads obtained via reactions catalyzed by triethylamine (a, b: $0.39 \% \mathrm{w} / \mathrm{w})$, or tri(n-butyl)amine (c, d: $0.039 \% \mathrm{w} / \mathrm{w})$. Scale bar: $2 \mu \mathrm{m}$. Reprinted by permission of Taylor \& Francis Ltd., http://www.tandfonline.com, Ref. [111].

\subsection{PBO Aerogel Beads}

There is only one example in the literature for particulate PBO aerogels. Reported fabrication of PBO aerogel particles from the reaction of 4,4'-isopropylidenediphenol, aniline and paraformaldehyde catalyzed by $\mathrm{HCl}$ [54]. The synthetic process was similar to the one described for PI aerogel powders derived from PMDA, DMBZ and TAB, as described in the previous section [54]. Compared to PIs, PBO particles had a more regular spherical shape, particulate (instead of fibrous) microstructure (Figure 17) and lower BET surface areas, which did not differ significantly to the ones of the corresponding monoliths (55.4-57.8 $\left.\mathrm{m}^{2} \mathrm{~g}^{-1}\right)$. However, PBO microparticles had twice the pore volume in the $1.7-300 \mathrm{~nm}$ range than the corresponding monoliths $\left(0.20\right.$ versus $\left.0.10 \mathrm{~cm}^{3} \mathrm{~g}^{-1}\right)$, which was attributed to lower shrinkage. The mean diameter of PBO microspheres was $32.7 \mu \mathrm{m}$ and they had a $100 \mathrm{~nm}$ thick dense skin layer. SEM images showed that the internal structure of PBO microparticles consisted of smaller spheres itself.
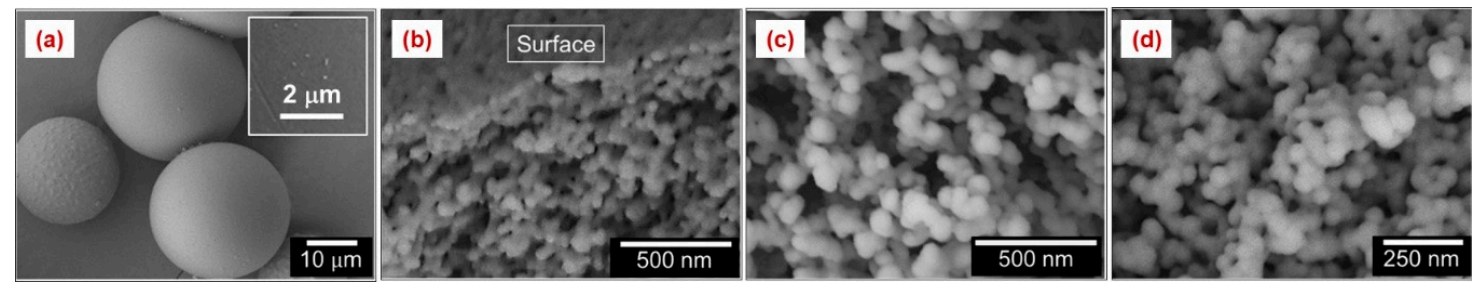

Figure 17. SEM image of: (a) PBO aerogel microparticles (inset: surface of the sphere), (b) fractured surface of PBZ aerogel microparticles, and (c,d) ensemble of spherical polybenzoxazine domains that formed the internal structure of aerogel microparticles and monolith, respectively. Adapted with permission from Ref. [54]. Copyright 2016 American Chemical Society.

\section{Conclusions}

Despite the vast literature on monolithic aerogels derived from synthetic polymers, including aerogels based on phenolic resins (e.g., resorcinol-formaldehyde and polybenzoxazines), polyureas, polyimides, polyamides, polyurethanes, and ROMP-derived aerogels, including polynorbornene and polydicyclopentadiene, only a few examples of synthetic polymer aerogels in particulate form have been described in the literature up to date, and have therefore been the subject of this mini-review. Aerogels classified as particulate include materials in the form of powders, irregular granules and spherical beads. Polymeric aerogels prepared in those forms include mostly polyurea aerogels derived 
from the reaction of isocyanates with amines or water under four different conditions: (a) disruption of gelation by vigorous agitation of the sol (powders and granules), (b) addition of non-solvents in the sol (powders and granules), (c) emulsion polymerization with surfactants (powders, granules. microspheres), and (d) dripping of the sol in a non-solvent (millimeter-size beads). Polyimide aerogels have also been synthesized from pyromellitic dianhydride and amines via (a) vigorous agitation of the sol (powders), (b) emulsion polymerization (powders), and (c) by mixing of polyamic acid sols with acetone as a supercritical fluid (spherical particles). Finally, phenolic type aerogels from resorcinol-formaldehyde and polybenzoxazine have been prepared in particulate form (beads) via emulsion and suspension polymerization processes, as well as with the dripping method. Table 3 summarizes all methods that have been utilized for the preparation of particulate aerogels from synthetic polymers. Manufacturing aerogels in a particulate rather than a monolithic form renders the bulk product rather insensitive to defects (e.g., cracks), reduces processing times, broadens the horizon of possible applications (as adsorbers, desiccants, additives for foods, cosmetics, construction materials, vehicles for drug delivery, etc.) via the one size fits all approach, and overall brings aerogels closer to consumer products. With respect to the most well-established application of aerogels as thermal insulators, the empty space between the particles compromises thermal conductivity. A solution to that problem will involve the packing of multi-dispersed particles.

Table 3. Summary of the synthetic methods used for the preparation of aerogel particles from synthetic polymers reviewed in this work.

\begin{tabular}{ccc}
\hline Type of Aerogel & Synthetic Method & References \\
\hline Polyurea (PUA) & Precipitation polymerization & {$[88-90]$} \\
\hline & Vigorous agitation & this work \\
\hline & Suspension polymerization & this work \\
\hline & Emulsion polymerization & this work \\
\hline Polyimide (PI) & Dripping method & {$[94]$} \\
\hline & Mechanical agitation & {$[98]$} \\
\hline & Emulsion polymerization & {$[54]$} \\
\hline Resorcinol-formaldehyde (RF) & Heating in an autoclave & {$[99]$} \\
\hline & Emulsion polymerization & {$[48]$} \\
\hline & Inverse suspension & {$[49]$} \\
\hline Polybenzoxazine (PBO) & polymerization & {$[53]$} \\
\hline & Injection emulsification & {$[111]$} \\
\hline & Dripping method & {$[54]$} \\
\hline
\end{tabular}

Supplementary Materials: The following are available online at http://www.mdpi.com/1996-1944/12/9/1543/s1: Experimental Section (1. Materials; 2. Methods and Equipment; 3. Synthetic Procedures), Table S1: Formulations of PUA powders from Desmodur N3300 for preparation in acetone via Vigorous Agitation, Table S2: Formulations of PUA powders from Desmodur N3300 for preparation in PC via Vigorous Agitation, Table S3: Formulations of PUA powders from Desmodur N3300 for preparation in PC/hexane via Suspension Polymerization, Table S4: Formulations of PUA powders from Desmodur N3300 for preparation in PC/hexane via Emulsion Polymerization, Table S5: Formulations of PUA powders from Desmodur RE for preparation via Vigorous Agitation or via Precipitation Polymerization.

Author Contributions: P.P. conceived and designed the experiments; D.C. performed the experiments; all authors analyzed the data; P.P. and G.R. wrote the paper; all authors have read and approved the paper.

Funding: This project has received funding from the European Union's Horizon 2020 research and innovation programme under grant agreement No 685648. This publication reflects the views only of the authors, and the Commission cannot be held responsible for any use, which may be made of the information contained therein.

Acknowledgments: We are thankful to Covestro AG for kindly providing samples of Desmodur N3300 and Desmodur RE and to Nikko Chemicals Co. for kindly providing samples of NIKKOL BL-9EX. 
Conflicts of Interest: The authors declare no conflicts of interest.

\section{References}

1. Leventis, N.; Sadekar, A.; Chandrasekaran, N.; Sotiriou-Leventis, C. Click Synthesis of Monolithic Silicon Carbide Aerogels from Polyacrylonitrile-Coated 3D Silica Networks. Chem. Mater. 2010, 22, 2790-2803. [CrossRef]

2. Vareda, J.P.; Lamy-Mendes, A.; Durães, L. A reconsideration on the definition of the term aerogel based on current drying trends. Microporous Mesoporous Mater. 2018, 258, 211-216. [CrossRef]

3. Tillotson, T.M.; Hrubesh, L.W. Transparent ultralow-density silica aerogels prepared by a two-step sol-gel process. J. Non-Cryst. Solids 1992, 145, 44-50. [CrossRef]

4. Pierre, A.C.; Pajonk, G.M. Chemistry of Aerogels and Their Applications. Chem. Rev. 2002, 102, 4243-4266. [CrossRef] [PubMed]

5. Aegerter, M.A.; Leventis, N.; Koebel, M.M. Aerogels Handbook; Springer Science \& Business Media: Berlin, Germany, 2011; ISBN 978-1-4419-7589-8.

6. Kistler, S.S. Coherent Expanded Aerogels and Jellies. Nature 1931, 127, 741. [CrossRef]

7. Kistler, S.S. The Relation between Heat Conductivity and Structure in Silica Aerogel. J. Phys. Chem. 1934, 39, 79-86. [CrossRef]

8. Kistler, S.S. Coherent Expanded-Aerogels. J. Phys. Chem. 1931, 36, 52-64. [CrossRef]

9. Kistler, S.; Swann, S.; Appel, E.G. Aerogel Catalysts-Thoria: Preparation of Catalyst and Conversions of Organic Acids to Ketones. Ind. Eng. Chem. 1934, 26, 388-391. [CrossRef]

10. Kistler, S.S. Method of Making Aerogels. US Patent 2249767A, 22 July 1941.

11. Peri, J.B. Infrared Study of $\mathrm{OH}$ and $\mathrm{NH}_{2}$ Groups on the Surface of a Dry Silica Aerogel. J. Phys. Chem. 1966, 70, 2937-2945. [CrossRef]

12. Pierre, A.C. History of Aerogels. In Aerogels Handbook; Aegerter, M.A., Leventis, N., Koebel, M.M., Eds.; Advances in Sol-Gel Derived Materials and Technologies; Springer: New York, NY, USA, 2011; pp. 3-18. ISBN 978-1-4419-7477-8.

13. Rolison, D.R.; Dunn, B. Electrically conductive oxide aerogels: newmaterials in electrochemistry. J. Mater. Chem. 2001, 11, 963-980. [CrossRef]

14. Al-Muhtaseb, S.A.; Ritter, J.A. Preparation and Properties of Resorcinol-Formaldehyde Organic and Carbon Gels. Adv. Mater. 2003, 15, 101-114. [CrossRef]

15. Du, A.; Zhou, B.; Zhang, Z.; Shen, J. A Special Material or a New State of Matter: A Review and Reconsideration of the Aerogel. Materials 2013, 6, 941-968. [CrossRef]

16. Biener, J.; Stadermann, M.; Suss, M.; Worsley, M.A.; Biener, M.M.; Rose, K.A.; Baumann, T.F. Advanced carbon aerogels for energy applications. Energy Environ. Sci. 2011, 4, 656-667. [CrossRef]

17. Antonietti, M.; Fechler, N.; Fellinger, T.-P. Carbon Aerogels and Monoliths: Control of Porosity and Nanoarchitecture via Sol-Gel routes. Chem. Mater. 2014, 26, 196-210. [CrossRef]

18. Lavoine, N.; Bergström, L. Nanocellulose-based foams and aerogels: processing, properties, and applications. J. Mater. Chem. A 2017, 5, 16105-16117. [CrossRef]

19. Li, F.; Xie, L.; Sun, G.; Kong, Q.; Su, F.; Cao, Y.; Wei, J.; Ahmad, A.; Guo, X.; Chen, C.-M. Resorcinol-formaldehyde based carbon aerogel: Preparation, structure and applications in energy storage devices. Microporous Mesoporous Mater. 2019, 279, 293-315. [CrossRef]

20. Akimov, Yu.K. Fields of Application of Aerogels (Review). Instrum. Exp. Tech. 2003, 46, 287-299. [CrossRef]

21. Baetens, R.; Jelle, B.P.; Gustavsen, A. Aerogel insulation for building applications: A state-of-the-art review. Energy Build. 2011, 43, 761-769. [CrossRef]

22. Koebel, M.; Rigacci, A.; Achard, P. Aerogel-based thermal superinsulation: an overview. J. Sol-Gel Sci. Technol. 2012, 63, 315-339. [CrossRef]

23. Cuce, E.; Cuce, P.M.; Wood, C.J.; Riffat, S.B. Toward aerogel based thermal superinsulation in buildings: A comprehensive review. Renew. Sustain. Energy Rev. 2014, 34, 273-299. [CrossRef]

24. Zhao, S.; Malfait, W.J.; Guerrero-Alburquerque, N.; Koebel, M.M.; Nyström, G. Biopolymer Aerogels and Foams: Chemistry, Properties, and Applications. Angew. Chem. Int. Ed. 2018, 57, 7580-7608. [CrossRef]

25. Villasmil, W.; Fischer, L.J.; Worlitschek, J. A review and evaluation of thermal insulation materials and methods for thermal energy storage systems. Renew. Sustain. Energy Rev. 2019, 103, 71-84. [CrossRef] 
26. Amonette, J.E.; Matyáš, J. Functionalized silica aerogels for gas-phase purification, sensing, and catalysis: A review. Microporous Mesoporous Mater. 2017, 250, 100-119. [CrossRef]

27. Maleki, H. Recent advances in aerogels for environmental remediation applications: A review. Chem. Eng. J. 2016, 300, 98-118. [CrossRef]

28. Kumar, A.; Rana, A.; Sharma, G.; Sharma, S.; Naushad, Mu.; Mola, G.T.; Dhiman, P.; Stadler, F.J. Aerogels and metal-organic frameworks for environmental remediation and energy production. Environ. Chem. Lett. 2018, 16, 797-820. [CrossRef]

29. Moreno-Castilla, C.; Maldonado-Hódar, F.J. Carbon aerogels for catalysis applications: An overview. Carbon 2005, 43, 455-465. [CrossRef]

30. Wan, W.; Zhang, R.; Ma, M.; Zhou, Y. Monolithic aerogel photocatalysts: A review. J. Mater. Chem. A 2018, 6, 754-775. [CrossRef]

31. Maleki, H.; Hüsing, N. Current status, opportunities and challenges in catalytic and photocatalytic applications of aerogels: Environmental protection aspects. Appl. Catal. B Environ. 2018, 221, 530-555. [CrossRef]

32. Mikkonen, K.S.; Parikka, K.; Ghafar, A.; Tenkanen, M. Prospects of polysaccharide aerogels as modern advanced food materials. Trends Food Sci. Technol. 2013, 34, 124-136. [CrossRef]

33. Kirkbir, F.; Murata, H.; Meyers, D.; Chaudhuri, S.R.; Sarkar, A. Drying and sintering of sol-gel derived large $\mathrm{SiO} 2$ monoliths. J. Sol-Gel Sci. Technol. 1996, 6, 203-217. [CrossRef]

34. Smirnova, I.; Gurikov, P. Aerogels in Chemical Engineering: Strategies Toward Tailor-Made Aerogels. Annu. Rev. Chem. Biomol. Eng. 2017, 8, 307-334. [CrossRef]

35. European Commision. New generation of nanoporous organic and hybrid aerogels for industrial applications. Available online: https://cordis.europa.eu/project/rcn/199829/factsheet/en (accessed on 9 May 2019).

36. Ganesan, K.; Budtova, T.; Ratke, L.; Gurikov, P.; Baudron, V.; Preibisch, I.; Niemeyer, P.; Smirnova, I.; Milow, B. Review on the Production of Polysaccharide Aerogel Particles. Materials 2018, 11, 2144. [CrossRef]

37. Preibisch, I.; Niemeyer, P.; Yusufoglu, Y.; Gurikov, P.; Milow, B.; Smirnova, I. Polysaccharide-Based Aerogel Bead Production via Jet Cutting Method. Materials 2018, 11, 1287. [CrossRef]

38. Baudron, V.; Gurikov, P.; Smirnova, I. A continuous approach to the emulsion gelation method for the production of aerogel micro-particle. Colloids Surf. Physicochem. Eng. Asp. 2019, 566, 58-69. [CrossRef]

39. Smirnova, I.; Gurikov, P. Aerogel production: Current status, research directions, and future opportunities. J. Supercrit. Fluids 2018, 134, 228-233. [CrossRef]

40. Guise, M.T.; Hosticka, B.; Earp, B.C.; Norris, P.M. An experimental investigation of aerosol collection utilizing packed beds of silica aerogel microspheres. J. Non-Cryst. Solids 2001, 285, 317-322. [CrossRef]

41. Quevedo, J.; Patel, G.; Pfeffer, R.; Dave, R. Agglomerates and granules of nanoparticles as filter media for submicron particles. Powder Technol. 2008, 183, 480-500. [CrossRef]

42. Buratti, C.; Merli, F.; Moretti, E. Aerogel-based materials for building applications: Influence of granule size on thermal and acoustic performance. Energy Build. 2017, 152, 472-482. [CrossRef]

43. Kumar Rajanna, S.; Vinjamur, M.; Mukhopadhyay, M. Mechanism for formation of Hollow and Granular Silica Aerogel Microspheres from rice husk ash for drug delivery. J. Non-Cryst. Solids 2015, 429, 226-231. [CrossRef]

44. Alnaief, M.; Smirnova, I. In situ production of spherical aerogel microparticles. J. Supercrit. Fluids 2011, 55, 1118-1123. [CrossRef]

45. Huber, L.; Zhao, S.; Malfait, W.J.; Vares, S.; Koebel, M.M. Fast and Minimal-Solvent Production of Superinsulating Silica Aerogel Granulate. Angew. Chem. Int. Ed. 2017, 56, 4753-4756. [CrossRef] [PubMed]

46. Zong, S.; Wei, W.; Jiang, Z.; Yan, Z.; Zhu, J.; Xie, J. Characterization and comparison of uniform hydrophilic/hydrophobic transparent silica aerogel beads: skeleton strength and surface modification. RSC Adv. 2015, 5, 55579-55587. [CrossRef]

47. Yu, Y.; Guo, D.; Fang, J. A Facile and Fast Gelation Process to Prepare Highly Spherical Millimeter-Sized Silica Aerogel Beads. Int. J. Appl. Ceram. Technol. 2015, 12, E244-E248. [CrossRef]

48. Horikawa, T.; Hayashi, J.; Muroyama, K. Size control and characterization of spherical carbon aerogel particles from resorcinol-formaldehyde resin. Carbon 2004, 42, 169-175. [CrossRef]

49. Liu, N.; Zhang, S.; Fu, R.; Dresselhaus, M.S.; Dresselhaus, G. Carbon aerogel spheres prepared via alcohol supercritical drying. Carbon 2006, 44, 2430-2436. [CrossRef] 
50. Yamamoto, T.; Ohmori, T.; Kim, Y.H. Preparation and characterization of monodisperse carbon cryogel microspheres. Microporous Mesoporous Mater. 2008, 112, 211-218. [CrossRef]

51. Wang, X.; Liu, L.; Wang, X.; Bai, L.; Wu, H.; Zhang, X.; Yi, L.; Chen, Q. Preparation and performances of carbon aerogel microspheres for the application of supercapacitor. J. Solid State Electrochem. 2011, 15, 643-648. [CrossRef]

52. Wang, X.; Wang, X.; Liu, L.; Bai, L.; An, H.; Zheng, L.; Yi, L. Preparation and characterization of carbon aerogel microspheres by an inverse emulsion polymerization. J. Non-Cryst. Solids 2011, 357, 793-797. [CrossRef]

53. Chaichanawong, J.; Kongcharoen, K.; Areerat, S. Preparation of carbon aerogel microspheres by a simple-injection emulsification method. Adv. Powder Technol. 2013, 24, 891-896. [CrossRef]

54. Gu, S.; Zhai, C.; Jana, S.C. Aerogel Microparticles from Oil-in-Oil Emulsion Systems. Langmuir 2016, 32, 5637-5645. [CrossRef]

55. Mulik, S.; Sotiriou-Leventis, C.; Leventis, N. Time-Efficient Acid-Catalyzed Synthesis of Resorcinol-Formaldehyde Aerogels. Chem. Mater. 2007, 19, 6138-6144. [CrossRef]

56. Pekala, R.W. Organic aerogels from the polycondensation of resorcinol with formaldehyde. J. Mater. Sci. 1989, 24, 3221-3227. [CrossRef]

57. Pekala, R.W. Low Density, Resorcinol-Formaldehyde Aerogels. US Patent 4997804A, 10 October 1989.

58. Pekala, R.W.; Alviso, C.T.; Kong, F.M.; Hulsey, S.S. Aerogels derived from multifunctional organic monomers. J. Non-Cryst. Solids 1992, 145, 90-98. [CrossRef]

59. Pekala, R.W.; Schaefer, D.W. Structure of organic aerogels. 1. Morphology and scaling. Macromolecules 1993, 26, 5487-5493. [CrossRef]

60. Mulik, S.; Sotiriou-Leventis, C.; Leventis, N. Macroporous Electrically Conducting Carbon Networks by Pyrolysis of Isocyanate-Cross-Linked Resorcinol-Formaldehyde Aerogels. Chem. Mater. 2008, 20, 6985-6997. [CrossRef]

61. ElKhatat, A.M.; Al-Muhtaseb, S.A. Advances in Tailoring Resorcinol-Formaldehyde Organic and Carbon Gels. Adv. Mater. 2011, 23, 2887-2903. [CrossRef]

62. Lorjai, P.; Chaisuwan, T.; Wongkasemjit, S. Porous structure of polybenzoxazine-based organic aerogel prepared by sol-gel process and their carbon aerogels. J. Sol-Gel Sci. Technol. 2009, 52, 56-64. [CrossRef]

63. Lorjai, P.; Wongkasemjit, S.; Chaisuwan, T.; Jamieson, A.M. Significant enhancement of thermal stability in the non-oxidative thermal degradation of bisphenol-A/aniline based polybenzoxazine aerogel. Polym. Degrad. Stab. 2011, 96, 708-718. [CrossRef]

64. Mahadik-Khanolkar, S.; Donthula, S.; Sotiriou-Leventis, C.; Leventis, N. Polybenzoxazine Aerogels. 1. High-Yield Room-Temperature Acid-Catalyzed Synthesis of Robust Monoliths, Oxidative Aromatization, and Conversion to Microporous Carbons. Chem. Mater. 2014, 26, 1303-1317. [CrossRef]

65. Gu, S.; Li, Z.; Miyoshi, T.; Jana, S.C. Polybenzoxazine aerogels with controllable pore structures. RSC Adv. 2015, 5, 26801-26805. [CrossRef]

66. Leventis, N.; Donthula, S. Chapter 34-HCl-Catalyzed Polymerization of Benzoxazine and Chemical Transformations Along Pyrolysis to Microporous Carbons. In Advanced and Emerging Polybenzoxazine Science and Technology; Ishida, H., Froimowicz, P., Eds.; Elsevier: Amsterdam, Netherlands, 2017; pp. 673-695. ISBN 978-0-12-804170-3.

67. Leventis, N.; Sotiriou-Leventis, C.; Chandrasekaran, N.; Mulik, S.; Larimore, Z.J.; Lu, H.; Churu, G.; Mang, J.T. Multifunctional Polyurea Aerogels from Isocyanates and Water. A Structure-Property Case Study. Chem. Mater. 2010, 22, 6692-6710. [CrossRef]

68. Leventis, N.; Chidambareswarapattar, C.; Bang, A.; Sotiriou-Leventis, C. Cocoon-in-Web-Like Superhydrophobic Aerogels from Hydrophilic Polyurea and Use in Environmental Remediation. ACS Appl. Mater. Interfaces 2014, 6, 6872-6882. [CrossRef]

69. Leventis, N.; Sotiriou-Leventis, C.; Saeed, A.M.; Donthula, S.; Majedi Far, H.; Rewatkar, P.M.; Kaiser, H.; Robertson, J.D.; Lu, H.; Churu, G. Nanoporous Polyurea from a Triisocyanate and Boric Acid: A Paradigm of a General Reaction Pathway for Isocyanates and Mineral Acids. Chem. Mater. 2016, 28, 67-78. [CrossRef]

70. Rhine, W.; Wang, J.; Begag, R. Polyimide Aerogels, Carbon Aerogels, and Metal Carbide Aerogels and Methods of Making Same. US Patent 20040132845A1, 11 July 2006.

71. Chidambareswarapattar, C.; Larimore, Z.; Sotiriou-Leventis, C.; Mang, J.T.; Leventis, N. One-step room-temperature synthesis of fibrous polyimide aerogels from anhydrides and isocyanates and conversion to isomorphic carbons. J. Mater. Chem. 2010, 20, 9666. [CrossRef] 
72. Meador, M.A.B.; Malow, E.J.; Silva, R.; Wright, S.; Quade, D.; Vivod, S.L.; Guo, H.; Guo, J.; Cakmak, M. Mechanically Strong, Flexible Polyimide Aerogels Cross-Linked with Aromatic Triamine. ACS Appl. Mater. Interfaces 2012, 4, 536-544. [CrossRef] [PubMed]

73. Chidambareswarapattar, C.; Xu, L.; Sotiriou-Leventis, C.; Leventis, N. Robust monolithic multiscale nanoporous polyimides and conversion to isomorphic carbons. RSC Adv. 2013, 3, 26459-26469. [CrossRef]

74. Meador, M.A.B.; Alemán, C.R.; Hanson, K.; Ramirez, N.; Vivod, S.L.; Wilmoth, N.; McCorkle, L. Polyimide Aerogels with Amide Cross-Links: A Low Cost Alternative for Mechanically Strong Polymer Aerogels. ACS Appl. Mater. Interfaces 2015, 7, 1240-1249. [CrossRef] [PubMed]

75. Leventis, N.; Chidambareswarapattar, C.; Mohite, D.P.; Larimore, Z.J.; Lu, H.; Sotiriou-Leventis, C. Multifunctional porous aramids (aerogels) by efficient reaction of carboxylic acids and isocyanates. J. Mater. Chem. 2011, 21, 11981-11986. [CrossRef]

76. Williams, J.C.; Meador, M.A.B.; McCorkle, L.; Mueller, C.; Wilmoth, N. Synthesis and Properties of Step-Growth Polyamide Aerogels Cross-linked with Triacid Chlorides. Chem. Mater. 2014, 26, 4163-4171. [CrossRef]

77. Chidambareswarapattar, C.; McCarver, P.M.; Luo, H.; Lu, H.; Sotiriou-Leventis, C.; Leventis, N. Fractal Multiscale Nanoporous Polyurethanes: Flexible to Extremely Rigid Aerogels from Multifunctional Small Molecules. Chem. Mater. 2013, 25, 3205-3224. [CrossRef]

78. Bang, A.; Buback, C.; Sotiriou-Leventis, C.; Leventis, N. Flexible Aerogels from Hyperbranched Polyurethanes: Probing the Role of Molecular Rigidity with Poly(Urethane Acrylates) Versus Poly(Urethane Norbornenes). Chem. Mater. 2014, 26, 6979-6993. [CrossRef]

79. Donthula, S.; Mandal, C.; Leventis, T.; Schisler, J.; Saeed, A.M.; Sotiriou-Leventis, C.; Leventis, N. Shape Memory Superelastic Poly(isocyanurate-urethane) Aerogels (PIR-PUR) for Deployable Panels and Biomimetic Applications. Chem. Mater. 2017, 29, 4461-4477. [CrossRef]

80. Donthula, S.; Mandal, C.; Schisler, J.; Leventis, T.; Meador, M.A.B.; Sotiriou-Leventis, C.; Leventis, N. Nanostructure-Dependent Marcus-Type Correlation of the Shape Recovery Rate and the Young's Modulus in Shape Memory Polymer Aerogels. ACS Appl. Mater. Interfaces 2018, 10, 23321-23334. [CrossRef]

81. Kanellou, A.; Anyfantis, G.C.; Chriti, D.; Raptopoulos, G.; Pitsikalis, M.; Paraskevopoulou, P. Poly (urethane-norbornene) Aerogels via Ring Opening Metathesis Polymerization of Dendritic Urethane-Norbornene Monomers: Structure-Property Relationships as a Function of an Aliphatic Versus an Aromatic Core and the Number of Peripheral Norbornene Moieties. Molecules 2018, 23, 1007. [CrossRef] [PubMed]

82. Papastergiou, M.; Kanellou, A.; Chriti, D.; Raptopoulos, G.; Paraskevopoulou, P. Poly(Urethane-Acrylate) Aerogels via Radical Polymerization of Dendritic Urethane-Acrylate Monomers. Materials 2018, 11, 2249. [CrossRef] [PubMed]

83. Papastergiou, M.; Chriti, D.; Damalas, D.E.; Raptopoulos, G.; Paraskevopoulou, P. Poly(urethane-acrylate) aerogels from the isocyanurate trimer of isophorone diisocyanate. J. Supercrit. Fluids 2019, 148, 42-54. [CrossRef]

84. Lee, J.K.; Gould, G.L. Polydicyclopentadiene based aerogel: a new insulation material. J. Sol-Gel Sci. Technol. 2007, 44, 29-40. [CrossRef]

85. Kim, S.H.; Worsley, M.A.; Valdez, C.A.; Shin, S.J.; Dawedeit, C.; Braun, T.; Baumann, T.F.; Letts, S.A.; Kucheyev, S.O.; Wu, K.J.J.; et al. Exploration of the versatility of ring opening metathesis polymerization: an approach for gaining access to low density polymeric aerogels. RSC Adv. 2012, 2, 8672-8680. [CrossRef]

86. Mohite, D.P.; Mahadik-Khanolkar, S.; Luo, H.; Lu, H.; Sotiriou-Leventis, C.; Leventis, N. Polydicyclopentadiene aerogels grafted with PMMA: I. Molecular and interparticle crosslinking. Soft Matter 2013, 9, 1516-1530. [CrossRef]

87. Lenhardt, J.M.; Kim, S.H.; Worsley, M.A.; Leif, R.N.; Campbell, P.G.; Baumann, T.F.; Satcher, J.H. ROMP crosslinkers for the preparation of aliphatic aerogels. J. Non-Cryst. Solids 2015, 408, 98-101. [CrossRef]

88. Moon, S.-Y.; Bae, J.-S.; Jeon, E.; Park, J.-W. Organic Sol-Gel Synthesis: Solution-Processable Microporous Organic Networks. Angew. Chem. Int. Ed. 2010, 49, 9504-9508. [CrossRef] [PubMed]

89. Moon, S.-Y.; Jeon, E.; Bae, J.-S.; Byeon, M.; Park, J.-W. Polyurea networks via organic sol-gel crosslinking polymerization of tetrafunctional amines and diisocyanates and their selective adsorption and filtration of carbon dioxide. Polym. Chem. 2014, 5, 1124-1131. [CrossRef]

90. Yang, Y.; Jiang, X.; Zhu, X.; Kong, X.Z. A facile pathway to polyurea nanofiber fabrication and polymer morphology control in copolymerization of oxydianiline and toluene diisocyanate in acetone. RSC Adv. 2014, 5, 7426-7432. [CrossRef] 
91. Taghvaee, T.; Donthula, S.; Rewatkar, P.M.; Majedi Far, H.; Sotiriou-Leventis, C.; Leventis, N. K-Index: A Descriptor, Predictor, and Correlator of Complex Nanomorphology to Other Material Properties. ACS Nano 2019, 13, 3677-3690. [CrossRef] [PubMed]

92. Saeed, A.M.; Rewatkar, P.M.; Majedi Far, H.; Taghvaee, T.; Donthula, S.; Mandal, C.; Sotiriou-Leventis, C.; Leventis, N. Selective CO2 Sequestration with Monolithic Bimodal Micro/Macroporous Carbon Aerogels Derived from Stepwise Pyrolytic Decomposition of Polyamide-Polyimide-Polyurea Random Copolymers. ACS Appl. Mater. Interfaces 2017, 9, 13520-13536. [CrossRef] [PubMed]

93. Carr, R.I. Evaluating flow properties of solids. 1965, 72, 163-168.

94. Chriti, D.; Raptopoulos, G.; Papastergiou, M.; Paraskevopoulou, P. Millimeter-Size Spherical Polyurea Aerogel Beads with Narrow Size Distribution. Gels 2018, 4, 66. [CrossRef]

95. Sroog, C.E. Polyimides. Prog. Polym. Sci. 1991, 16, 561-694. [CrossRef]

96. Meador, M.A.B.; Johnston, J.C.; Cavano, P.J. Elucidation of the Cross-Link Structure of Nadic-End-Capped Polyimides Using NMR of ${ }^{13}$ C-Labeled Polymers. Macromolecules 1997, 30, 515-519. [CrossRef]

97. Meador, M.A. Recent Advances in the Development of Processable High-Temperature Polymers. Annu. Rev. Mater. Sci. 1998, 28, 599-630. [CrossRef]

98. Wu, Q.; Pan, L.; Wang, H.; Deng, W.; Yang, G.; Liu, X. A green and scalable method for producing high-performance polyimide aerogels using low-boiling-point solvents and sublimation drying. Polym. J. 2015, 48, 169-175. [CrossRef]

99. Kwon, J.; Kim, J.; Yoo, T.; Park, D.; Han, H. Preparation and Characterization of Spherical Polyimide Aerogel Microparticles. Macromol. Mater. Eng. 2014, 299, 1081-1088. [CrossRef]

100. Kawagishi, K.; Saito, H.; Furukawa, H.; Horie, K. Superior Nanoporous Polyimides via Supercritical CO2 Drying of Jungle-Gym-Type Polyimide Gels. Macromol. Rapid Commun. 2007, 28, 96-100. [CrossRef]

101. Barbieri, O.; Ehrburger-Dolle, F.; Rieker, T.P.; Pajonk, G.M.; Pinto, N.; Venkateswara Rao, A. Small-angle X-ray scattering of a new series of organic aerogels. J. Non-Cryst. Solids 2001, 285, 109-115. [CrossRef]

102. Merzbacher, C.I.; Meier, S.R.; Pierce, J.R.; Korwin, M.L. Carbon aerogels as broadband non-reflective materials. J. Non-Cryst. Solids 2001, 285, 210-215. [CrossRef]

103. Brandt, R.; Fricke, J. Acetic-acid-catalyzed and subcritically dried carbon aerogels with a nanometer-sized structure and a wide density range. J. Non-Cryst. Solids 2004, 350, 131-135. [CrossRef]

104. Brandt, R.; Petricevic, R.; Pröbstle, H.; Fricke, J. Acetic Acid Catalyzed Carbon Aerogels. J. Porous Mater. 2003, 10, 171-178. [CrossRef]

105. Ishida, H.; Agag, T. Handbook of Benzoxazine Resins; Elsevier: Amsterdam, Netherlands, 2011; ISBN 978-0-444-53791-1.

106. Holly, F.W.; Cope, A.C. Condensation Products of Aldehydes and Ketones with o-Aminobenzyl Alcohol and o-Hydroxybenzylamine. J. Am. Chem. Soc. 1944, 66, 1875-1879. [CrossRef]

107. Ning, X.; Ishida, H. Phenolic materials via ring-opening polymerization: Synthesis and characterization of bisphenol-A based benzoxazines and their polymers. J. Polym. Sci. Part Polym. Chem. 1994, 32, 1121-1129. [CrossRef]

108. Ning, X.; Ishida, H. Phenolic materials via ring-opening polymerization of benzoxazines: Effect of molecular structure on mechanical and dynamic mechanical properties. J. Polym. Sci. Part B Polym. Phys. 1994, 32, 921-927. [CrossRef]

109. Ishida, H. Process for Preparation of Benzoxazine Compounds in Solventless SAystems. US Patent US5543516A, 6 August 1996.

110. Kumar, K.S.S.; Nair, C.P.R. Polybenzoxazines: Chemistry and Properties; ISmithers: Shrewsburry, UK, 2010; ISBN 978-1-84735-501-0.

111. Ito, F.; Nakamura, N.; Nagai, K.; Nakai, M.; Norimatsu, T. Smooth Membrane Formation on Resorcinol-Formaldehyde Aerogel Balls Gelated Using a Basic Phase-Transfer Catalyst. Fusion Sci. Technol. 2009, 55, 465-471. [CrossRef]

(C) 2019 by the authors. Licensee MDPI, Basel, Switzerland. This article is an open access article distributed under the terms and conditions of the Creative Commons Attribution (CC BY) license (http://creativecommons.org/licenses/by/4.0/). 